\title{
Root proteomic and metabolic analyses reveal specific responses to drought stress in differently tolerant grapevine rootstocks
}

\author{
Bhakti Prinsi, Alfredo Simone Negri, Osvaldo Failla, Attilio Scienza and Luca Espen * (1)
}

\begin{abstract}
Background: Roots play a central role in plant response to water stress (WS). They are involved in its perception and signalling to the leaf as well as in allowing the plant to adapt to maintaining an adequate water balance. Only a few studies have investigated the molecular/biochemical responses to WS in roots of perennial plants, such as grapevine. This study compares two grapevine rootstock genotypes (i.e. 101.14 and M4) with different tolerance to WS, evaluating the responses at proteomic and metabolite levels.

Results: WS induced changes in the abundance of several proteins in both genotypes (17 and 22\% of the detected proteins in 101.14 and M4, respectively). The proteomic analysis revealed changes in many metabolic pathways that fitted well with the metabolite data. M4 showed metabolic responses which were potentially able to counteract the WS effects, such as the drop in cell turgor, increased oxidative stress and loss of cell structure integrity/functionality. However, in 101.14 it was evident that the roots were suffering more severely from these effects. We found that many proteins classified as active in energy metabolism, hormone metabolism, protein, secondary metabolism and stress functional classes showed particular differences between the two rootstocks.

Conclusion: The proteomic/metabolite comparative analysis carried out provides new information on the possible biochemical and molecular strategies adopted by grapevine roots to counteract WS. Although further work is needed to define in detail the role(s) of the proteins and metabolites that characterize WS response, this study, involving the M4 rootstock genotype, highlights that osmotic responses, modulations of $\mathrm{C}$ metabolism, mitochondrial functionality and some specific responses to stress occurring in the roots play a primary role in Vitis spp. tolerance to this type of abiotic stress.
\end{abstract}

Keywords: Drought, Grapevine, Proteomics, Rootstock, Water stress

\section{Background}

Among the environmental problems related to viticulture, drought is one of the major factors that negatively affect grape production [1]. However, a significant part of the land devoted to viticulture, such as the Mediterranean regions of Europe, is located in areas characterized by a seasonal drought coinciding with the grapevine ripening period, thus affecting both yield and fruit quality [2-5]. Moreover, provisional studies on climate changes indicate that in these areas the availability of water will diminish in the coming years $[4,6]$.

\footnotetext{
*Correspondence: luca.espen@unimi.it

Dipartimento di Scienze Agrarie e Ambientali - Produzione, Territorio,

Agroenergia (DiSAA), Università degli Studi di Milano, Via Celoria, 2, 20133 Milano, Italy
}

Under drought, the grapevine leaf exhibits deep changes at molecular, biochemical, physiological and morphological levels which are useful to improve water use efficiency (WUE) through the activation of adaptive responses [2, 7-13]. Furthermore, it is clear that the strategy adopted in these adverse conditions can be somewhat different between grapevine cultivars (isohydric or anisohydric behaviours), besides being affected by pedo-climatic conditions $[3,9]$. Among the typical immediate responses observed in the leaf organ under water deficit, there is progressive stomatal closure to counteract the untenable water loss $[2,7,10]$. This response, mediated by both hydraulic and chemical signalling, has direct and severe effects on photosynthesis and therefore on biomass production $[2,12,14,15]$. Moreover, the reduction in water content 
leads to a loss of turgor with a consequent reduction of plant growth [7, 16]. In this condition, other typical responses in leaf tissues are osmotic adjustment, activation of ROS-scavenging mechanisms, changes in cell wall elasticity and metabolic acclimation $[7,9,17,18]$.

The recent literature reinforces the central role in the WS response of the roots, which take part in stress perception, adaptation and signaling to the aerial system, as well as their role in the uptake and transport of water towards the leaves $[9,14,19-21]$. In this context, many studies have highlighted that a positive plant response to WS is strictly dependent on the roots' capabilities of sustaining growth (i.e., changing the depth and density of the root system) and of maintaining/increasing the root hydraulic conductance [10, 13, 19-23]. Regarding this last aspect, the woody roots of perennial plants like grapevine, despite their low hydraulic conductance, can significantly contribute to water absorption from the soil [24].

Many studies indicate that the tolerance to WS of the root depends on its capability of maintaining adequate symplastic osmotic potential, cell wall protein composition, carbohydrate metabolism and the metabolic pathways involved in the oxidative stress response [25-28]. In agreement with this picture, two recent studies have also shown that in grapevine roots these responses play a central role in WS tolerance $[29,30]$.

In recent years, proteomic approaches have been undertaken to study WS responses. Some of this work focused attention on the roots of herbaceous species, such as soybean, wild watermelon, wheat, rapeseed and sugarcane [31]. These studies reported proteome changes linked to different biochemical responses, such as an increase in energy demand, transport activities, and the appearance or increase in the levels of proteins known to have protective roles under these stress conditions. In grapevine, the proteomic approach has been used to investigate the effects of WS in shoot and fruit tissues $[18,32,33]$. To our knowledge, to date no proteomic investigation has studied water stress responses in the roots of this perennial species.

Previously, the molecular, biochemical and physiological responses to WS of the novel rootstock genotype named M4 $[(V$. vinifera $\times \quad V$. berlandieri $) \times V$. berlandieri $\mathrm{cv}$. Resseguier no. 1] have been evaluated [29, 30]. The comparison with the genotype 101.14 (V. riparia $x \mathrm{~V}$. rupestris) highlighted the greater tolerance to WS of M4, as shown by photosynthetic parameters as well as by the analysis of molecular and biochemical responses in both leaf and root $[29,30]$.

The present study focused attention on the changes in root proteomes which occur in M4 and 101.14 rootstock genotypes under WS. The analyses were performed on samples obtained from the same experiments described by Meggio et al. and Corso et al. [29, 30], so allowing a high level of confidence between the proteomic results and the physiological, biochemical and molecular ones. The analyses were carried out to evaluate the proteomic changes induced by harsh WS conditions (i.e. reduction of the field soil capacity down to 30\%). Moreover, a metabolomic analysis was performed to obtain further information on the effects induced by WS on the main biochemical pathways, such as glycolysis and related sugar metabolism, the Krebs cycle and amino acid metabolisms. The results showed many differences between the two genotypes, so revealing specific traits linked to a low (101.14) or a high (M4) capability to tolerate WS conditions.

\section{Results}

Mass spectrum interpretation allowed us to identify and quantify a total of 972 and 788 unique proteins for the 101.14 and the M4 genotypes, respectively. The technical parameters concerning peptide validation and protein identification reported in (Additional file 1: Table S1) indicated the good reliability of the approach adopted.

The results obtained by the comparison within the two experimental conditions experienced by each genotype (i.e., control versus water-stressed plants) are reported in Tables 1 and 2 and (Additional file 2: Table S2 A and B).

The majority of the identified proteins did not change in abundance under WS, and this was named the "static proteome" (Fig. 1). In detail, the static proteome was 83 and $78 \%$ in the 101.14 and the M4 rootstock genotypes, respectively (Fig. 1a and b). Proteins that changed in abundance in WS were 181 and 186 for 101.14 and M4, respectively. Among these, 48 were identified only in 101.14, whereas 64 were found only in M4 (Additional file 3: Table S3 A, B and C). Small differences occurred between proteins that appeared (named "new", 2 and $1 \%$ in 101.14 and M4, respectively) or disappeared ( 2 and 3\% in 101.14 and M4, respectively) in WS. Moreover, 9\% of the proteins decreased in abundance in both genotypes, while the accumulated proteins were 4 and $9 \%$ in 101.14 and M4, respectively (Fig. 1a and b).

Functional classification was made according to the bin hierarchical tree developed by MapMan ontology [34] using a Vitis vinifera mapping file (see Methods for details; Additional file 3: Table S3 A and B for the data). In the control condition, the two rootstock genotypes showed a very similar functional distribution of the identified proteins (Fig. 2a and b for 101.14 and M4, respectively). About $50 \%$ of these fell into four functional categories: carbon and energy metabolism, protein, miscellaneous enzyme families and stress. Considering only the proteins that changed significantly in abundance, essentially all the functional categories were affected by WS, but the extent of these changes was very different in the two genotypes (Fig. 2c, d, e and f). Proteins that increased/appeared 
Table 1 Proteins showing significant changes in responses to WS in the 101.14 genotype

\begin{tabular}{|c|c|c|c|}
\hline n. & Name (f.c.) & Accession & $\Delta: \mathrm{WS} / \mathrm{C}$ \\
\hline \multicolumn{4}{|c|}{ Carbon and energy metabolism $(1,2,3,4,5,6,7,8,9,25)$} \\
\hline 97 & $\begin{array}{l}\text { unnamed protein product - sucrose } \\
\text { synthase 2-like (2) }\end{array}$ & CBI35298.3 & new \\
\hline 397 & fumarate hydratase 1, mitochondrial (8) & XP_002273033.1 & new \\
\hline 595 & $\begin{array}{l}\text { alpha-1,4 glucan phosphorylase } \mathrm{L} \text { isozyme, } \\
\text { chloroplastic/amyloplastic-like (2) }\end{array}$ & XP_002279075.2 & 39.40 \\
\hline 559 & $\begin{array}{l}\text { aldehyde dehydrogenase family } 7 \text { member } \\
\text { A1 }(5,8,20)\end{array}$ & XP_002278093.1 & 6.14 \\
\hline 938 & $\begin{array}{l}\text { ATP-citrate synthase alpha chain protein } \\
2 \text { isoform } 2(8)\end{array}$ & XP_003633614.1 & 5.55 \\
\hline 222 & $\begin{array}{l}\text { glucose-6-phosphate 1-dehydrogenase, } \\
\text { cytoplasmic isoform (7) }\end{array}$ & XP_002266527.1 & 3.56 \\
\hline 368 & sucrose synthase 2 (2) & XP_002271896.1 & 2.86 \\
\hline 818 & 1,4-alpha-glucan-branching enzyme-like (2) & XP_002284841.2 & 2.43 \\
\hline 443 & $\begin{array}{l}\text { triosephosphate isomerase, chloroplastic-like } \\
\text { isoform } 1 \text { (1) }\end{array}$ & XP_002274871.1 & -2.12 \\
\hline 432 & enolase 1 , chloroplastic-like (4) & XP_002274334.1 & -2.18 \\
\hline 269 & fructokinase-2 (2) & XP_002268097.1 & -2.38 \\
\hline 158 & $\begin{array}{l}\text { pyruvate dehydrogenase E1 component } \\
\text { subunit beta, mitochondrial-like isoform } 1 \text { (8) }\end{array}$ & XP_002264210.1 & -2.53 \\
\hline 350 & $\begin{array}{l}\text { dihydrolipoyllysine-residue acetyltransferase } \\
\text { component } \\
\text { of pyruvate dehydrogenase complex, } \\
\text { mitochondrial-like isoform } 1 \text { (8) }\end{array}$ & XP_002271286.1 & -2.94 \\
\hline 698 & $\begin{array}{l}\text { dihydrolipoyllysine-residue acetyltransferase } \\
\text { component of pyruvate dehydrogenase } \\
\text { complex, mitochondrial-like }(8,11)\end{array}$ & XP_002282287.1 & -3.24 \\
\hline 307 & $\begin{array}{l}\text { pyrophosphate-fructose 6-phosphate } \\
\text { 1-phosphotransferase subunit beta-like (4) }\end{array}$ & XP_002269934.2 & -3.40 \\
\hline 622 & $\begin{array}{l}\text { pyruvate kinase isozyme } A \text {, chloroplastic } \\
\text { isoform } 1(4,11)\end{array}$ & XP_002279975.1 & -3.71 \\
\hline 507 & dihydrolipoyl dehydrogenase $(8,11,21)$ & XP_002276853.1 & -4.56 \\
\hline 301 & $\begin{array}{l}\text { pyruvate dehydrogenase E1 component } \\
\text { subunit beta }(1,8,11)\end{array}$ & XP_002269441.1 & -8.46 \\
\hline 236 & $\begin{array}{l}\text { glucose-6-phosphate 1-dehydrogenase, } \\
\text { chloroplastic }(7,30)\end{array}$ & XP_002266930.1 & -25.91 \\
\hline 280 & $\begin{array}{l}\text { succinate dehydrogenase [ubiquinone] } \\
\text { iron-sulfur subunit } 1 \text {, mitochondrial }(8,29)\end{array}$ & XP_002268523.1 & d. \\
\hline 551 & carbonic anhydrase, chloroplastic $(8,16)$ & XP_002277957.1 & d. \\
\hline \multicolumn{4}{|c|}{ Cell Wall (10) } \\
\hline 273 & UDP-glucose 4-epimerase GEPI48 (10) & XP_002268294.2 & 4.34 \\
\hline 282 & $\begin{array}{l}\text { beta-xylosidase/alpha-L-arabinofuranosidase } \\
\text { 2-like }(10,33)\end{array}$ & XP_002268626.2 & -2.68 \\
\hline 620 & probable UDP-arabinopyranose mutase 5 (10) & XP_002279911.1 & -2.27 \\
\hline 423 & $\begin{array}{l}\text { probable xyloglucan endotransglucosylase/hydrolase } \\
\text { protein } 30 \text {-like (10) }\end{array}$ & XP_002273975.1 & -3.28 \\
\hline 702 & probable rhamnose biosynthetic enzyme 1 (10) & XP_002282339.1 & -5.93 \\
\hline \multicolumn{4}{|c|}{ Lipid Metabolism (11) } \\
\hline 248 & long chain acyl-CoA synthetase 8 (11) & XP_002267417.1 & new \\
\hline 312 & $\begin{array}{l}\text { glyoxysomal fatty acid beta-oxidation multifunctional } \\
\text { protein MFP-a (11) }\end{array}$ & XP_002270067.1 & 50.99 \\
\hline 271 & phospholipase D alpha $1(11,27)$ & XP_002268195.1 & 2.46 \\
\hline
\end{tabular}


Table 1 Proteins showing significant changes in responses to WS in the 101.14 genotype (Continued)

\begin{tabular}{|c|c|c|c|}
\hline n. & Name (f.c.) & Accession & $\Delta: W S / C$ \\
\hline 564 & $\begin{array}{l}\text { biotin carboxyl carrier protein of acetyl-CoA } \\
\text { carboxylase-like (11) }\end{array}$ & XP_002278151.2 & -2.86 \\
\hline 183 & $\begin{array}{l}\text { 3-oxoacyl-[acyl-carrier-protein] synthase I, } \\
\text { chloroplastic-like (11) }\end{array}$ & XP_002265207.1 & -3.09 \\
\hline 942 & phospholipase C 4-like isoform 2 (11) & XP_003633883.1 & -3.12 \\
\hline 219 & biotin carboxylase 1, chloroplastic-like (11) & XP_002266489.1 & -3.58 \\
\hline 268 & $\begin{array}{l}\text { 3-oxoacyl-[acyl-carrier-protein] reductase, } \\
\text { chloroplastic }(11,26)\end{array}$ & XP_002268080.1 & -3.71 \\
\hline 775 & $\begin{array}{l}\text { acyl-CoA-binding domain-containing protein } \\
\text { 4-like isoform } 1 \text { (11) }\end{array}$ & XP_002284019.1 & -4.32 \\
\hline 958 & flavoprotein wrbA isoform 2 (11) & XP_003634692.1 & d. \\
\hline \multicolumn{4}{|c|}{$N$ and amino acid metabolism $(12,13)$} \\
\hline 3 & S-adenosylmethionine synthase $2(13,15)$ & A7NVX9.1 & -2.13 \\
\hline 929 & glyoxylate reductase isoform $2(1,13,26)$ & XP_003632860.1 & -2.34 \\
\hline 971 & $\begin{array}{l}\text { phosphoserine aminotransferase, } \\
\text { chloroplastic-like }(13,27)\end{array}$ & XP_003635669.1 & -2.36 \\
\hline 843 & ferredoxin-nitrite reductase, chloroplastic (12) & XP_002285208.1 & -2.65 \\
\hline 518 & $\begin{array}{l}\text { serine hydroxymethyltransferase, } \\
\text { mitochondrial }(1,13,25)\end{array}$ & XP_002277146.1 & -2.92 \\
\hline 318 & $\begin{array}{l}\text { bifunctional 3-dehydroquinate dehydratase/shikimate } \\
\text { dehydrogenase, chloroplastic (13) }\end{array}$ & XP_002270188.1 & -4.84 \\
\hline 206 & adenosylhomocysteinase isoform 1 (13) & XP_002266154.1 & -5.43 \\
\hline 321 & $\begin{array}{l}\text { bifunctional 3-dehydroquinate dehydratase/shikimate } \\
\text { dehydrogenase, chloroplastic-like (13) }\end{array}$ & XP_002270232.1 & -6.15 \\
\hline 212 & $\begin{array}{l}\text { probable S-adenosylmethionine-dependent } \\
\text { methyltransferase At5g37990-like }(13,17)\end{array}$ & XP_002266288.2 & -7.51 \\
\hline 342 & methionine S-methyltransferase-like (13) & XP_002270977.1 & -10.04 \\
\hline 687 & ornithine carbamoyltransferase, chloroplastic (13) & XP_002281919.1 & -10.33 \\
\hline 186 & alanine aminotransferase 2 (13) & XP_002265294.2 & -10.94 \\
\hline \multicolumn{4}{|c|}{ Secondary metabolism (16) } \\
\hline 576 & $\begin{array}{l}\text { 2-C-methyl-D-erythritol 2,4-cyclodiphosphate } \\
\text { synthase, chloroplastic-like (16) }\end{array}$ & XP_002278406.1 & new \\
\hline 392 & aldo-keto reductase family 4 member C9-like $(3,16)$ & XP_002272909.1 & -2.10 \\
\hline 136 & 3-isopropylmalate dehydratase small subunit (16) & XP_002263405.1 & -2.26 \\
\hline 549 & isopentenyl-diphosphate Delta-isomerase I-like (16) & XP_002277935.1 & -2.59 \\
\hline 717 & $\begin{array}{l}\text { 1-deoxy-D-xylulose 5-phosphate reductoisomerase, } \\
\text { chloroplastic (16) }\end{array}$ & XP_002282761.1 & -2.76 \\
\hline 836 & $\begin{array}{l}\text { 4-hydroxy-3-methylbut-2-en-1-yl diphosphate } \\
\text { synthase (16) }\end{array}$ & XP_002285130.1 & -3.06 \\
\hline 960 & $\begin{array}{l}\text { bifunctional dihydroflavonol 4-reductase/flavanone } \\
\text { 4-reductase-like }(16,26,29)\end{array}$ & XP_003634871.1 & -6.69 \\
\hline 106 & chalcone-flavonone isomerase $1(16,27)$ & P51117.1 & d. \\
\hline 373 & protein SRG1 (16) & XP_002272119.1 & d. \\
\hline 525 & zeta-carotene desaturase, chloroplastic/chromoplastic (16) & XP_002277348.2 & d. \\
\hline 557 & REF/SRPP-like protein At1g67360-like (16) & XP_002278036.1 & d. \\
\hline 584 & $\begin{array}{l}\text { carotenoid 9,10(9',10')-cleavage dioxygenase } \\
1 \text {-like }(16,17)\end{array}$ & XP_002278628.1 & d. \\
\hline \multicolumn{4}{|c|}{ Hormone metabolism (17) } \\
\hline 617 & auxin-repressed $12.5 \mathrm{kDa}$ protein isoform $1(17,27,33)$ & XP_002279836.1 & new \\
\hline 591 & auxin-induced protein PCNT115 isoform $1(17,26)$ & XP_002278850.1 & 2.93 \\
\hline
\end{tabular}


Table 1 Proteins showing significant changes in responses to WS in the 101.14 genotype (Continued)

\begin{tabular}{|c|c|c|c|}
\hline n. & Name (f.c.) & Accession & $\Delta: \mathrm{WS} / \mathrm{C}$ \\
\hline 148 & linoleate 13S-lipoxygenase 2-1, chloroplastic (17) & XP_002263854.1 & 2.55 \\
\hline 457 & HVA22-like protein a (17) & XP_002275428.1 & 2.29 \\
\hline 828 & gibberellin 20 oxidase 3 -like $(16,17,26)$ & XP_002284983.1 & -2.15 \\
\hline 767 & $\begin{array}{l}\text { probable indole-3-acetic acid-amido } \\
\text { synthetase GH3.1 (17) }\end{array}$ & XP_002283886.1 & -2.23 \\
\hline 825 & gibberellin 20 oxidase $3(16,17,26)$ & XP_002284968.1 & -7.11 \\
\hline 54 & $\begin{array}{l}\text { hypothetical protein VITISV_007808 } \\
\text { (gibberellin 3-beta-dioxygenase 1) }(17,26)\end{array}$ & CAN66061.1 & -14.90 \\
\hline 897 & 1-aminocyclopropane-1-carboxylate oxidase 5 (17) & XP_002285881.1 & d. \\
\hline \multicolumn{4}{|c|}{ Stress (20) } \\
\hline 132 & $22.0 \mathrm{kDa}$ heat shock protein (20) & XP_002263376.1 & new \\
\hline 436 & auxin-binding protein ABP19a-like (20) & XP_002274457.1 & new \\
\hline 513 & $\begin{array}{l}\text { putative germin-like protein } 2-1 \\
(12,20,27,30,34)\end{array}$ & XP_002277055.1 & new \\
\hline 636 & 18.2 kDa class I heat shock protein $(20,29)$ & XP_002280353.1 & new \\
\hline 900 & MLP-like protein 28-like (20) & XP_003631204.1 & new \\
\hline 652 & 18.2 kDa class I heat shock protein $(20,29)$ & XP_002280821.1 & 21.56 \\
\hline 810 & MLP-like protein 34 (20) & XP_002284578.1 & 2.92 \\
\hline 349 & universal stress protein $\mathrm{A}$-like protein $(20,27,33)$ & XP_002271154.1 & 2.14 \\
\hline 152 & stress-related protein-like (16) & XP_002263944.1 & 2.12 \\
\hline 798 & $\begin{array}{l}\text { germin-like protein subfamily } \\
1 \text { member } 17(12,20,27,34)\end{array}$ & XP_002284436.1 & -2.50 \\
\hline 677 & chitinase $2(20,21)$ & XP_002281729.1 & -3.28 \\
\hline 566 & germin-like protein $9-3(15,20)$ & XP_002278170.1 & -4.10 \\
\hline 44 & $\begin{array}{l}\text { hypothetical protein VITISV_005677 } \\
\text { (germin-like protein 9-3) }(15,20)\end{array}$ & CAN61171.1 & -14.62 \\
\hline 64 & $\begin{array}{l}\text { hypothetical protein VITISV_005471 } \\
\text { (germin-like protein 1) }(12,20,27,34)\end{array}$ & CAN71140.1 & d. \\
\hline 237 & $\begin{array}{l}\text { putative germin-like protein } \\
2-1(12,20,27,30,34)\end{array}$ & XP_002266984.1 & d. \\
\hline 240 & $\begin{array}{l}\text { putative germin-like protein } \\
2-1(12,20,27,30,34)\end{array}$ & XP_002267172.1 & d. \\
\hline 867 & pathogen-related protein (20) & XP_002285489.1 & d. \\
\hline \multicolumn{4}{|c|}{ Redox (21) } \\
\hline 205 & $\begin{array}{l}\text { glutathione S-transferase DHAR3, } \\
\text { chloroplastic (21) }\end{array}$ & XP_002266106.1 & new \\
\hline 482 & glutaredoxin (21) & XP_002276266.1 & 3.29 \\
\hline 754 & peroxiredoxin-2E, chloroplastic (21) & XP_002283652.1 & -2.01 \\
\hline 334 & catalase isozyme 1 isoform 1 (21) & XP_002270703.2 & -3.41 \\
\hline \multicolumn{4}{|c|}{ Miscellaneous enzyme families (26) } \\
\hline 845 & $\begin{array}{l}\text { probable glutathione S-transferase } \\
(26,28,33)\end{array}$ & XP_002285214.1 & new \\
\hline 36 & $\begin{array}{l}\text { hypothetical protein VITISV_041925 - } \\
\text { carboxymethylenebutenolidase (26) }\end{array}$ & CAN60148.1 & 2.41 \\
\hline 633 & peroxidase $3(20,26)$ & XP_002280274.1 & 2.27 \\
\hline 23 & glutathione S-transferase $5(11,16,26)$ & ABW34390.1 & 2.11 \\
\hline 445 & (+)-neomenthol dehydrogenase-like isoform 2 (26) & XP_002274970.2 & -2.01 \\
\hline 396 & minor allergen Alt a 7 -like $(11,26,27)$ & XP_002273030.1 & -2.16 \\
\hline 427 & probable inactive purple acid phosphatase 1 -like $(26,27)$ & XP_002274118.2 & -2.29 \\
\hline
\end{tabular}


Table 1 Proteins showing significant changes in responses to WS in the 101.14 genotype (Continued)

\begin{tabular}{|c|c|c|c|}
\hline n. & Name (f.c.) & Accession & $\Delta: \mathrm{WS} / \mathrm{C}$ \\
\hline 338 & epoxide hydrolase 2 (26) & XP_002270883.2 & -2.29 \\
\hline 286 & probable glutathione S-transferase (26) & XP_002268911.1 & -2.45 \\
\hline 840 & NADP-dependent alkenal double bond reductase P1 $(26,34)$ & XP_002285167.1 & -47.43 \\
\hline \multicolumn{4}{|c|}{ DNA/RNA $(27,28)$} \\
\hline 281 & proactivator polypeptide-like 1 isoform 1 (28) & XP_002268581.1 & new \\
\hline 623 & ribonuclease 3 (27) & XP_002280078.1 & new \\
\hline 755 & putative DNA repair protein RAD23-3 isoform $1(28,29)$ & XP_002283656.1 & -2.49 \\
\hline 164 & KH domain-containing protein At4g18375 isoform 1 (27) & XP_002264417.1 & -5.48 \\
\hline \multicolumn{4}{|c|}{ Protein (29) } \\
\hline 99 & unnamed protein product (pseudouridine synthase) (29) & CBI39540.3 & new \\
\hline 759 & outer envelope pore protein 16, chloroplastic (29) & XP_002283749.1 & new \\
\hline 803 & eukaryotic translation initiation factor 3 subunit E (29) & XP_002284533.1 & new \\
\hline 829 & vesicle-fusing ATPase-like (29) & XP_002284987.1 & new \\
\hline 252 & protease Do-like 1, chloroplastic-like (29) & XP_002267510.2 & 7.32 \\
\hline 154 & aspartic proteinase nepenthesin- $1(27,29)$ & XP_002263964.1 & 4.86 \\
\hline 924 & 40 S ribosomal protein S15a-like isoform 2 (29) & XP_003632608.1 & 4.08 \\
\hline 794 & N-carbamoyl-L-amino acid hydrolase-like (29) & XP_002284376.1 & 3.95 \\
\hline 196 & 265 proteasome non-ATPase regulatory subunit 1-like (29) & XP_002265758.2 & 2.39 \\
\hline 279 & serine carboxypeptidase-like 18 (29) & XP_002268517.1 & -2.00 \\
\hline 774 & acylamino-acid-releasing enzyme-like isoform 1 (29) & XP_002284013.2 & -2.25 \\
\hline 768 & aspartic proteinase nepenthesin-1-like $(27,29)$ & XP_002283889.2 & -2.31 \\
\hline 641 & uncharacterized protein LOC100259133 (m.: 29, 33) & XP_002280454.1 & -2.58 \\
\hline 50 & $\begin{array}{l}\text { hypothetical protein VITISV_017087 (serine } \\
\text { carboxypeptidase II-3-like) (29) }\end{array}$ & CAN63486.1 & -2.86 \\
\hline 651 & pyrrolidone-carboxylate peptidase isoform 4 (29) & XP_002280794.1 & -2.92 \\
\hline 722 & protein transport protein Sec24-like At3g07100-like (29) & XP_002282857.1 & -3.18 \\
\hline 701 & serine carboxypeptidase II-3-like (29) & XP_002282331.1 & -3.30 \\
\hline 65 & hypothetical protein VITISV_003230 (m.: 29) & CAN71580.1 & -3.78 \\
\hline 679 & cucumisin-like (29) & XP_002281790.2 & -4.22 \\
\hline 522 & cucumisin-like (29) & XP_002277242.2 & -5.96 \\
\hline 689 & serine carboxypeptidase II-3-like (29) & XP_002281988.1 & -6.70 \\
\hline 311 & $\begin{array}{l}\text { probable serine/threonine-protein kinase } \\
\text { At5g41260 (29) }\end{array}$ & XP_002270065.1 & -12.57 \\
\hline 720 & serine carboxypeptidase-like 45-like (29) & XP_002282852.1 & -15.26 \\
\hline 58 & hypothetical protein VITISV_026357 (m.: 29, 30, 33) & CAN68006.1 & -51.68 \\
\hline 470 & cucumisin-like (29) & XP_002275807.1 & -106.41 \\
\hline 303 & $\begin{array}{l}\text { uncharacterized protein LOC100254416 } \\
\text { (pathogenesis-related protein 17) (29) }\end{array}$ & XP_002269470.1 & d. \\
\hline 721 & subtilisin-like protease-like $(29,30)$ & XP_002282856.1 & d. \\
\hline \multicolumn{4}{|c|}{ Cell / signaling / development $(30,31,33)$} \\
\hline 140 & 70 kDa peptidyl-prolyl isomerase $(29,31)$ & XP_002263566.2 & new \\
\hline 357 & actin-depolymerizing factor 10 (31) & XP_002271495.1 & new \\
\hline 744 & $\begin{array}{l}\text { transmembrane emp24 domain-containing } \\
\text { protein A (31) }\end{array}$ & XP_002283487.1 & new \\
\hline 163 & $\begin{array}{l}\text { uncharacterized protein LOC100255239 } \\
\text { (calcium ion binding protein) (30) }\end{array}$ & XP_002264359.1 & 5.11 \\
\hline 799 & glutelin type-A $1(28,33)$ & XP_002284459.1 & 4.50 \\
\hline
\end{tabular}


Table 1 Proteins showing significant changes in responses to WS in the 101.14 genotype (Continued)

\begin{tabular}{|c|c|c|c|}
\hline n. & Name (f.c.) & Accession & $\Delta: W S / C$ \\
\hline 415 & calnexin homolog 1 (30) & XP_002273708.1 & 4.47 \\
\hline 644 & $\begin{array}{l}\text { uncharacterized protein LOC100266227 } \\
\text { (Late embryogenesis abundant } \\
\text { protein Lea14-A) (33) }\end{array}$ & XP_002280489.1 & 4.09 \\
\hline 934 & VAMP-like protein YKT61-like (31) & XP_003633163.1 & 3.26 \\
\hline 740 & $\begin{array}{l}\text { oxysterol-binding protein-related } \\
\text { protein } 3 C(31)\end{array}$ & XP_002283434.1 & -2.07 \\
\hline 676 & $\begin{array}{l}\text { uncharacterized protein HI_0488 } \\
\text { (phosphatase YqaB) (33) }\end{array}$ & XP_002281714.1 & -2.18 \\
\hline 332 & $\begin{array}{l}\text { coatomer subunit epsilon-1 } \\
\text { isoform } 1 \text { (31) }\end{array}$ & XP_002270662.1 & -2.35 \\
\hline 599 & $\begin{array}{l}\text { nitrogen regulatory protein } \\
\text { P-II homolog (30) }\end{array}$ & XP_002279289.1 & -2.60 \\
\hline 907 & $\begin{array}{l}\text { uncharacterized protein } \\
\text { LOC100854676 (m.: 30) }\end{array}$ & XP_003631533.1 & -3.20 \\
\hline 735 & DAG protein, chloroplastic isoform 1 (33) & XP_002283211.1 & -3.83 \\
\hline 245 & tubulin beta-1 chain isoform 1 (31) & XP_002267304.1 & -4.10 \\
\hline 374 & golgin candidate 6 -like $(29,31)$ & XP_002272168.1 & -4.22 \\
\hline 560 & PRA1 family protein B4-like $(30,31)$ & XP_002278095.1 & d. \\
\hline \multicolumn{4}{|c|}{ Transport (34) } \\
\hline 704 & $\begin{array}{l}\text { pyrophosphate-energized vacuolar membrane } \\
\text { proton pump } 1 \text { (34) }\end{array}$ & XP_002282358.1 & 2.76 \\
\hline 870 & uncharacterized protein LOC100240897 (m.: 34) & XP_002285517.1 & 2.29 \\
\hline 548 & aquaporin TIP2-3 (34) & XP_002277904.2 & -5.27 \\
\hline \multicolumn{4}{|c|}{ Others $(15,18,23,24)$} \\
\hline 86 & unnamed protein product (DJ-1 family protein) (18) & CBI20205.3 & new \\
\hline 516 & ferritin-3, chloroplastic (15) & XP_002277114.1 & 6.49 \\
\hline 731 & $\begin{array}{l}\text { NAD-dependent dihydropyrimidine dehydrogenase } \\
\text { subunit PreA (23) }\end{array}$ & XP_002283095.1 & 5.41 \\
\hline 700 & $\begin{array}{l}\text { ectonucleotide pyrophosphatase/phosphodiesterase } \\
\text { family member } 3 \text { (23) }\end{array}$ & XP_002282308.1 & 4.52 \\
\hline 95 & $\begin{array}{l}\text { unnamed protein product (nucleoside } \\
\text { diphosphate kinase) (23) }\end{array}$ & CBI34488.3 & 3.07 \\
\hline 639 & $\begin{array}{l}\text { 6,7-dimethyl-8-ribityllumazine synthase, } \\
\text { chloroplastic-like (18) }\end{array}$ & XP_002280427.1 & 2.58 \\
\hline 492 & guanine deaminase (23) & XP_002276494.1 & -2.41 \\
\hline 123 & $\begin{array}{l}\text { nucleoside diphosphate kinase 2, chloroplastic } \\
\text { isoform } 1 \text { (23) }\end{array}$ & XP_002263177.1 & -3.31 \\
\hline 894 & biotin-protein ligase (18) & XP_002285834.1 & -4.28 \\
\hline 535 & probable carboxylesterase 15 (24) & XP_002277507.1 & -7.50 \\
\hline 90 & $\begin{array}{l}\text { unnamed protein product (soluble inorganic } \\
\text { pyrophosphatase) (23) }\end{array}$ & CBI25065.3 & d. \\
\hline 161 & selT-like protein (15) & XP_002264265.1 & d. \\
\hline \multicolumn{4}{|c|}{ Hypothetical / Unknown function (35) } \\
\hline 76 & unknown protein (35) & CAQ58595.1 & new \\
\hline 85 & unnamed protein product (Protein tolB) (35) & CBI18981.3 & new \\
\hline 230 & protein LURP-one-related 15 (35) & XP_002266795.1 & new \\
\hline 902 & probable nucleoredoxin 1-like (35) & XP_003631263.1 & 2.99 \\
\hline 127 & uncharacterized protein At5g48480 (35) & XP_002263284.1 & 2.81 \\
\hline 387 & pre-mRNA-processing factor 39-like (35) & XP_002272685.1 & -2.36 \\
\hline
\end{tabular}


Table 1 Proteins showing significant changes in responses to WS in the 101.14 genotype (Continued)

\begin{tabular}{clll}
\hline $\mathrm{n}$. & Name (f.c.) & Accession & $\Delta:$ WS/C \\
\hline 420 & uncharacterized protein LOC100242710 (35) & XP_002273917.1 & -2.44 \\
361 & putative phosphatidylglycerol/phosphatidylinositol & XP_002271535.1 & \\
& transfer protein DDB_G0282179 isoform 1 (35) & XP_002285168.1 & -3.07 \\
841 & putative clathrin assembly protein At2925430-like (35) & XP_002265851.1 & -3.35 \\
199 & uncharacterized protein LOC100265424 (35) & XP_002266892.1 & -4.35 \\
232 & uncharacterized protein LOC100253185 (35) & XP_002273566.1 & -4.68 \\
412 & S-norcoclaurine synthase (35) & CAN62850.1 & -4.92 \\
48 & hypothetical protein VITISV_010154 (35) & XP_002277989.1 & -6.76 \\
553 & transmembrane protein 111 (35) & XP_002265225.1 & -7.13 \\
184 & NADPH:quinone oxidoreductase (35) & CBI17463.3 & -16.72 \\
82 & unnamed protein product (metal ion binding & XP_002278552.1 & d. \\
582 & protein, putative) (35) & XP_002285734.1 & d. \\
890 & clavaminate synthase-like protein At3g21360 (35) & uncharacterized protein LOC100254028 (35) &
\end{tabular}

Numbers reported in brackets refer to bin code (i.e. major functional categories). n.: identification number. f.c.: bin code of functional categories. Name: for proteins without a name in brackets are indicated the results from BLAST alignment against NCBI Viridiplantae database; $m$.: classification obtained through grape/Arabidopsis or grape/potato matching by BLASTp algorithm (E.value $<10^{-} 20$ ). $\Delta$ : fold changes in WS plants with respect to the Control ones (up: \%(SI)WS/\%(SI)C, down: - \%(SI)C/\%(SI)WS). new: not present in C; d.: disappeared, not present in WS

(64 and 84 for 101.14 and M4, respectively) were represented in all the functional categories. Interestingly, the 101.14 genotype did not show any increase of proteins involved in $\mathrm{N}$ and amino acid metabolism. Comparing the responses between the two genotypes, 101.14 showed a greater number of increased/appeared proteins concerned to lipid metabolism, hormone metabolism, miscellaneous enzyme families and others, while for all the remaining functional categories the number of accumulated proteins was generally higher in M4 (Fig. 2c and d for 101.14 and M4, respectively). An opposite response occurred for proteins that decreased/disappeared in WS, which were 117 and 102 for 101.14 and M4, respectively. Indeed, only in four functional categories, i.e., cell wall, stress, miscellaneous enzyme families and DNA/RNA, the number of proteins that decreased in abundance was higher in M4, while for essentially all the remaining categories the higher number was found in 101.14 (Fig. 2e and for 101.14 and M4, respectively).

\section{Main metabolic pathways of the primary metabolism}

The analysis of the nature of the proteins affected by WS highlighted changes in many metabolic pathways with particular differences between the two genotypes (Tables 1 and 2). For a better visualization, datasets containing all of the proteins identified in each genotype were used to produce heat maps concerning the overview of both the main metabolic pathways (Fig. 3) and those known to be involved in stress responses (Fig. 4).

WS led to deep changes in the functional classes of carbon and energy metabolism (Tables 1 and 2; Fig. 3;
Additional file 3: Table S3 C). In both rootstock genotypes, enzymes involved in starch mobilization (alpha-1,4 glucan phosphorylase L isozyme) or in the sucrose biosynthetic pathway (phosphoglucomutase, UTP-glucose-1-phosphate uridylyltransferase and glucose-6-phosphate isomerase) were found. On the basis of the observed changes in abundance, M4 showed a greater activation of these pathways. Moreover, an increase in sucrose synthase 2 , an enzyme involved in the degradation of this sugar, occurred only in 101.14.

Many of the changing proteins classified in the cell wall functional class decreased in abundance in WS (Tables 1 and 2; Figs. 3 and 4). Nevertheless, UDP-glucose 4-epimerase GEPI48, an enzyme that probably plays a central role in biosynthesis and growth of cell walls [35], rose during WS in both genotypes. Moreover, a xyloglucan endotransglucosylase/hydrolase protein B, an enzyme involved in wall loosening [28], showed an evident enhancement only in M4. In this genotype, the hypothetical protein VITISV_001144 (CAN61024.1), that shows a high similarity with some leucine-rich repeat (LRR) proteins, also surged up under WS.

Many plastidial enzymes, such as triosephosphate isomerase, enolase 1, pyruvate kinase isozyme A, ferredoxin-NADP reductase and glucose-6-phosphate 1-dehydrogenase, decreased in abundance under WS in both genotypes. Unlike the plastid isoform, the abundance of cytosolic glucose-6-phosphate dehydrogenase increased in both genotypes (Tables 1 and 2).

Some units of the pyruvate dehydrogenase complex (dihydrolipoyl dehydrogenase, E1 component subunit beta 
Table 2 Proteins showing significant changes in responses to WS in the M4 genotype

\begin{tabular}{|c|c|c|c|}
\hline n. & Name (f.c.) & Accession & $\Delta: W S / C$ \\
\hline \multicolumn{4}{|c|}{ Carbon and energy metabolism $(1,2,3,4,5,6,7,8,9,25)$} \\
\hline 474 & $\begin{array}{l}\text { alpha-1,4 glucan phosphorylase L isozyme, } \\
\text { chloroplastic/amyloplastic-like (2) }\end{array}$ & XP_002279075.2 & new \\
\hline 542 & $\begin{array}{l}\text { isocitrate dehydrogenase [NAD] catalytic } \\
\text { subunit } 5 \text {, mitochondrial-like (8) }\end{array}$ & XP_002281826.1 & 14.46 \\
\hline 231 & $\begin{array}{l}\text { succinate-semialdehyde dehydrogenase } \\
\text { (acetylating)-like }(5,26)\end{array}$ & XP_002268625.1 & 7.33 \\
\hline 481 & 2-oxoglutarate dehydrogenase, mitochondrial-like (8) & XP_002279332.2 & 6.00 \\
\hline 757 & ATP-citrate synthase alpha chain protein 2 isoform 2 (8) & XP_003633614.1 & 4.05 \\
\hline 463 & formate dehydrogenase, mitochondrial (25) & XP_002278444.1 & 3.05 \\
\hline 695 & $\begin{array}{l}\text { phosphoenolpyruvate carboxylase, } \\
\text { housekeeping isozyme isoform } 1 \text { (4) }\end{array}$ & XP_002285441.1 & 2.84 \\
\hline 446 & aldehyde dehydrogenase family 7 member $\mathrm{A} 1(5,8,20)$ & XP_002278093.1 & 2.34 \\
\hline 251 & L-idonate 5-dehydrogenase $(3,5,26)$ & XP_002269895.1 & 2.23 \\
\hline 626 & citrate synthase, glyoxysomal (6) & XP_002284064.1 & 2.20 \\
\hline 556 & $\begin{array}{l}\text { UTP-glucose-1-phosphate } \\
\text { uridylyltransferase isoform 1(4) }\end{array}$ & XP_002282276.1 & 2.20 \\
\hline 187 & $\begin{array}{l}\text { glucose-6-phosphate 1-dehydrogenase, } \\
\text { cytoplasmic isoform (7) }\end{array}$ & XP_002266527.1 & 2.16 \\
\hline 655 & phosphoglucomutase, cytoplasmic (4) & XP_002284729.1 & 2.01 \\
\hline 374 & pyruvate decarboxylase isozyme 1 (5) & XP_002275486.1 & -2.01 \\
\hline 718 & glucose-6-phosphate isomerase isoform 1 (4) & XP_002285696.1 & -2.12 \\
\hline 313 & pyruvate decarboxylase isozyme 2 (5) & XP_002272615.1 & -2.33 \\
\hline 116 & $\begin{array}{l}\text { ferredoxin-NADP reductase, root isozyme, } \\
\text { chloroplastic-like ( } 7)\end{array}$ & XP_002263658.2 & -2.40 \\
\hline 354 & enolase 1, chloroplastic-like (4) & XP_002274334.1 & -2.63 \\
\hline 269 & D-threo-aldose 1-dehydrogenase (2) & XP_002270562.1 & -2.65 \\
\hline 92 & L-idonate 5-dehydrogenase $(3,5)$ & Q1PSI9.2 & -2.93 \\
\hline 413 & dihydrolipoyl dehydrogenase $(8,11,21)$ & XP_002276853.1 & -3.52 \\
\hline 495 & $\begin{array}{l}\text { pyruvate kinase isozyme } A \text {, chloroplastic } \\
\text { isoform } 1(4,11)\end{array}$ & XP_002279975.1 & -3.79 \\
\hline 557 & $\begin{array}{l}\text { dihydrolipoyllysine-residue acetyltransferase } \\
\text { component of pyruvate dehydrogenase complex, } \\
\text { mitochondrial-like }(8,11)\end{array}$ & XP_002282287.1 & -4.11 \\
\hline 194 & $\begin{array}{l}\text { glucose-6-phosphate 1-dehydrogenase, } \\
\text { chloroplastic }(7,30)\end{array}$ & XP_002266930.1 & -19.38 \\
\hline \multicolumn{4}{|c|}{ Cell Wall (10) } \\
\hline 357 & $\begin{array}{l}\text { probable xyloglucan endotransglucosylase/hydrolase } \\
\text { protein B (10) }\end{array}$ & XP_002274520.1 & 11.89 \\
\hline 222 & UDP-glucose 4-epimerase GEPI48 (10) & XP_002268294.2 & 7.31 \\
\hline 34 & hypothetical protein VITISV_001144 (m.: 10) & CAN61024.1 & 3.39 \\
\hline 129 & beta-xylosidase/alpha-L-arabinofuranosidase 2-like $(10,33)$ & XP_002264183.2 & -2.07 \\
\hline 561 & probable rhamnose biosynthetic enzyme 1 (10) & XP_002282339.1 & -2.12 \\
\hline 772 & UDP-sugar pyrophospharylase isoform 2 (10) & XP_003634394.1 & -2.37 \\
\hline 508 & pectinesterase 2 (10) & XP_002280446.1 & -3.32 \\
\hline 12 & $\begin{array}{l}\text { acetyl-CoA carboxylase carboxyltransferase beta } \\
\text { subunit }(10,11,29)\end{array}$ & ABE47543.1 & d. \\
\hline 345 & probable xyloglucan endotransglucosylase/hydrolase & XP_002273975.1 & d. \\
\hline
\end{tabular}


Table 2 Proteins showing significant changes in responses to WS in the M4 genotype (Continued)

\begin{tabular}{|c|c|c|c|}
\hline n. & Name (f.c.) & Accession & $\Delta: \mathrm{WS} / \mathrm{C}$ \\
\hline \multicolumn{4}{|c|}{ Lipid Metabolism (11) } \\
\hline 253 & putative esterase HI_1161 isoform 1 (11) & XP_002269958.1 & new \\
\hline 219 & phospholipase D alpha $1(11,27)$ & XP_002268195.1 & 2.44 \\
\hline 152 & $\begin{array}{l}\text { 3-oxoacyl-[acyl-carrier-protein] synthase I, } \\
\text { chloroplastic-like (11) }\end{array}$ & XP_002265207.1 & -2.23 \\
\hline 451 & $\begin{array}{l}\text { biotin carboxyl carrier protein of acetyl-CoA } \\
\text { carboxylase-like (11) }\end{array}$ & XP_002278151.2 & -2.64 \\
\hline 216 & $\begin{array}{l}\text { 3-oxoacyl-[acyl-carrier-protein] reductase, } \\
\text { chloroplastic }(11,26)\end{array}$ & XP_002268080.1 & -3.72 \\
\hline 737 & $\begin{array}{l}\text { 3-oxoacyl-[acyl-carrier-protein] synthase } 3 \mathrm{~A} \text {, } \\
\text { chloroplastic-like (11) }\end{array}$ & XP_003631438.1 & -5.47 \\
\hline 623 & $\begin{array}{l}\text { acyl-CoA-binding domain-containing protein } \\
\text { 4-like isoform } 1 \text { (11) }\end{array}$ & XP_002284019.1 & -5.81 \\
\hline 648 & probable linoleate 9S-lipoxygenase 5 (11) & XP_002284535.2 & -7.06 \\
\hline 414 & $\begin{array}{l}\text { biotin carboxyl carrier protein of acetyl-CoA } \\
\text { carboxylase } 1 \text {, chloroplastic }(11,18)\end{array}$ & XP_002276955.2 & $\mathrm{d}$ \\
\hline \multicolumn{4}{|c|}{$N$ and amino acid metabolism $(12,13)$} \\
\hline 516 & arginase-like (13) & XP_002280690.2 & new \\
\hline 210 & $\begin{array}{l}\text { alanine-glyoxylate aminotransferase } 2 \text { homolog } 2, \\
\text { mitochondrial }(13,19)\end{array}$ & XP_002267787.1 & 5.42 \\
\hline 178 & $\begin{array}{l}\text { methylmalonate-semialdehyde dehydrogenase } \\
\text { [acylating], mitochondrial (13) }\end{array}$ & XP_002266390.1 & 5.29 \\
\hline 170 & adenosylhomocysteinase isoform 1 (13) & XP_002266154.1 & 2.99 \\
\hline 787 & phosphoserine aminotransferase, chloroplastic-like $(13,27)$ & XP_003635669.1 & -2.04 \\
\hline 763 & $\begin{array}{l}\text { 3-phosphoshikimate 1-carboxyvinyltransferase, } \\
\text { chloroplastic-like (13) }\end{array}$ & XP_003633923.1 & -3.63 \\
\hline 428 & $\begin{array}{l}\text { bifunctional 3-dehydroquinate dehydratase/shikimate } \\
\text { dehydrogenase, chloroplastic-like (13) }\end{array}$ & XP_002277395.2 & -4.68 \\
\hline 25 & glutamine synthetase (12) & CAA63982.1 & -8.64 \\
\hline 177 & $\begin{array}{l}\text { probable S-adenosylmethionine-dependent } \\
\text { methyltransferase At5g37990-like }(13,17)\end{array}$ & XP_002266288.2 & -30.63 \\
\hline 259 & hydroxyacylglutathione hydrolase 3, mitochondrial-like (13) & XP_002270140.1 & d. \\
\hline \multicolumn{4}{|c|}{ Secondary metabolism (16) } \\
\hline 230 & anthocyanidin 5,3-O-glucosyltransferase $(16,26)$ & XP_002268560.1 & new \\
\hline 766 & caffeic acid 3-O-methyltransferase 1-like isoform $1(16,26)$ & XP_003634161.1 & new \\
\hline 678 & probable $\mathrm{NAD}(\mathrm{P}) \mathrm{H}$-dependent oxidoreductase $1(3,16)$ & XP_002285219.1 & 12.08 \\
\hline 90 & chalcone-flavonone isomerase $1(16,27)$ & P51117.1 & 3.07 \\
\hline 206 & anthocyanidin 5,3-O-glucosyltransferase-like $(16,26)$ & XP_002267573.1 & 2.44 \\
\hline 135 & stilbene synthase 1 (16) & XP_002264455.1 & 2.32 \\
\hline 497 & chalcone-flavonone isomerase-like isoform 1 (16) & XP_002280158.1 & -2.09 \\
\hline 427 & probable cinnamyl alcohol dehydrogenase 1-like (16) & XP_002277375.1 & -2.88 \\
\hline 692 & probable cinnamyl alcohol dehydrogenase 1 (16) & XP_002285406.1 & -3.02 \\
\hline 574 & $\begin{array}{l}\text { 1-deoxy-D-xylulose 5-phosphate reductoisomerase, } \\
\text { chloroplastic (16) }\end{array}$ & XP_002282761.1 & -6.95 \\
\hline 247 & isoeugenol synthase 1 (16) & XP_002269639.1 & d. \\
\hline 670 & $\begin{array}{l}\text { 4-hydroxy-3-methylbut-2-en-1-yl } \\
\text { diphosphate synthase (16) }\end{array}$ & XP_002285130.1 & d. \\
\hline \multicolumn{4}{|c|}{ Hormone metabolism (17) } \\
\hline 471 & auxin-induced protein PCNT115 isoform $1(17,26)$ & XP_002278850.1 & 18.40 \\
\hline
\end{tabular}


Table 2 Proteins showing significant changes in responses to WS in the M4 genotype (Continued)

\begin{tabular}{|c|c|c|c|}
\hline $\mathrm{n}$. & Name (f.c.) & Accession & $\Delta: W S / C$ \\
\hline 121 & linoleate 135-lipoxygenase 2-1, chloroplastic (17) & XP_002263854.1 & 3.85 \\
\hline 515 & gibberellin 3-beta-dioxygenase $3(17,26)$ & XP_002280670.1 & $\mathrm{d}$ \\
\hline 662 & gibberellin 20 oxidase 3 -like $(16,17,26)$ & XP_002284983.1 & d. \\
\hline \multicolumn{4}{|c|}{ Stress (20) } \\
\hline 124 & stress-related protein-like (16) & XP_002263944.1 & new \\
\hline 715 & disease resistance response protein 206 (20) & XP_002285676.1 & new \\
\hline 581 & osmotin-like protein OSM34 (20) & XP_002282917.1 & 3.47 \\
\hline 653 & MLP-like protein 34 (20) & XP_002284578.1 & 7.22 \\
\hline 525 & osmotin-like protein (20) & XP_002281193.1 & 5.06 \\
\hline 91 & basic endochitinase (20) & P51613.1 & 2.93 \\
\hline 687 & $\begin{array}{l}\text { topless-related protein } 4 \text {-like isoform } \\
1(20,33)\end{array}$ & XP_002285341.2 & 2.45 \\
\hline 10 & chitinase class I basic (20) & ABD64684.1 & 2.38 \\
\hline 172 & putative germin-like protein $2-1(12,20,27,30,34)$ & XP_002266227.1 & 2.38 \\
\hline 254 & endoplasmin homolog (20) & XP_002270014.2 & 2.33 \\
\hline 649 & MLP-like protein 28-like isoform 1 (20) & XP_002284538.1 & 2.17 \\
\hline 652 & MLP-like protein $28(20)$ & XP_002284570.1 & 2.10 \\
\hline 359 & major allergen Pru av. $1(20,27,34)$ & XP_002274617.1 & 2.08 \\
\hline 780 & heat shock cognate protein 80-like (20) & XP_003635036.1 & 2.01 \\
\hline 346 & major allergen Pru ar $1(20,27,34)$ & XP_002273982.1 & -2.45 \\
\hline 643 & germin-like protein subfamily 1 member $17(20,27,34)$ & XP_002284436.1 & -2.82 \\
\hline 334 & germin-like protein 9-3 $(15,20)$ & XP_002273554.1 & -3.62 \\
\hline 195 & putative germin-like protein $2-1(12,20,27,30,34)$ & XP_002266984.1 & -4.25 \\
\hline 453 & germin-like protein $9-3(15,20)$ & XP_002278170.1 & -4.76 \\
\hline 537 & chitinase 2 (20) & XP_002281729.1 & -4.80 \\
\hline 102 & pathogen-related protein (20) & XP_002263121.1 & -7.46 \\
\hline 74 & unnamed protein product $(m .: 11,20)$ & CBI28159.3 & $\mathrm{d}$ \\
\hline 583 & putative endo-1,3(4)-beta-glucanase 2-like (20) & XP_002282971.1 & d. \\
\hline \multicolumn{4}{|c|}{ Redox (21) } \\
\hline 8 & catalase (21) & AAL83720.1 & 2.91 \\
\hline 714 & glutathione reductase, cytosolic (21) & XP_002285672.1 & 2.70 \\
\hline 607 & peroxiredoxin-2E, chloroplastic (21) & XP_002283652.1 & -2.02 \\
\hline \multicolumn{4}{|c|}{ Miscellaneous enzyme families (26) } \\
\hline 193 & glutathione transferase GST 23-like isoform $1(26,28,33)$ & XP_002266900.1 & 8.62 \\
\hline 777 & probable glutathione S-transferase parC-like isoform 2 (26) & XP_003634746.1 & 4.78 \\
\hline 15 & glutathione S-transferase (26) & ABL84692.1 & 2.08 \\
\hline 287 & tropinone reductase 1 -like (26) & XP_002271432.1 & -2.14 \\
\hline 274 & epoxide hydrolase 2 (26) & XP_002270883.2 & -2.40 \\
\hline 323 & glutathione S-transferase zeta class-like isoform 1 (26) & XP_002273077.1 & -2.59 \\
\hline 238 & glutathione S-transferase U9 (26) & XP_002269118.1 & -2.93 \\
\hline 236 & probable glutathione S-transferase (26) & XP_002268911.1 & -3.06 \\
\hline 674 & $\begin{array}{l}\text { NADP-dependent alkenal double bond } \\
\text { reductase P1 }(26,34)\end{array}$ & XP_002285167.1 & -3.38 \\
\hline 417 & I-Ala-D/L-Glu epimerase (26) & XP_002277056.1 & -3.45 \\
\hline 412 & UDP-glycosyltransferase 85A1-like $(17,26,29)$ & XP_002276823.1 & -3.84 \\
\hline
\end{tabular}


Table 2 Proteins showing significant changes in responses to WS in the M4 genotype (Continued)

\begin{tabular}{|c|c|c|c|}
\hline n. & Name (f.c.) & Accession & $\Delta: \mathrm{WS} / \mathrm{C}$ \\
\hline 197 & momilactone A synthase (26) & XP_002267041.1 & -4.51 \\
\hline 320 & momilactone A synthase-like (26) & XP_002272981.1 & -5.53 \\
\hline 127 & glutathione transferase GST 23 (26) & XP_002264054.1 & -7.67 \\
\hline 536 & glutathione S-transferase U7 isoform $1(26,28,33)$ & XP_002281654.1 & -9.51 \\
\hline 512 & probable glutathione S-transferase $(26,28,33)$ & XP_002280532.1 & -16.45 \\
\hline 527 & UDP-glycosyltransferase 83A1 (26) & XP_002281262.1 & d. \\
\hline 748 & epoxide hydrolase 2-like (26) & XP_003632381.1 & d. \\
\hline \multicolumn{4}{|c|}{ DNARNA $(27,28)$} \\
\hline 207 & DEAD-box ATP-dependent RNA helicase 37-like (27) & XP_002267581.2 & 31.87 \\
\hline 235 & DEAD-box ATP-dependent RNA helicase $56(27,28)$ & XP_002268833.1 & 11.78 \\
\hline 148 & transcription factor BTF3 $(27,34)$ & XP_002265041.1 & 4.42 \\
\hline 676 & polyadenylate-binding protein 2 (27) & XP_002285190.1 & -2.62 \\
\hline 502 & ribonuclease UK114-like (27) & XP_002280251.1 & -2.90 \\
\hline 39 & hypothetical protein VITISV_017556 (m.: 27) & CAN66609.1 & -3.96 \\
\hline 205 & uncharacterized protein LOC100253093 (m.: 27, 29, 34) & XP_002267536.1 & -5.72 \\
\hline 42 & $\begin{array}{l}\text { hypothetical protein VITISV_020351 (probable } \\
\text { ADP-ribosylation factor GTPase-activating protein AGD11) (27) }\end{array}$ & CAN67438.1 & d. \\
\hline 133 & KH domain-containing protein At4g18375 isoform 1 (27) & XP_002264417.1 & d. \\
\hline 240 & poly(rC)-binding protein 3-like (27) & XP_002269249.1 & d. \\
\hline \multicolumn{4}{|c|}{ Protein (29) } \\
\hline 180 & miraculin $(20,29,31)$ & XP_002266430.1 & 11.55 \\
\hline 651 & 265 proteasome non-ATPase regulatory subunit 14 (29) & XP_002284566.1 & 4.76 \\
\hline 387 & probable protein phosphatase $2 C 58$ (29) & XP_002275890.1 & 3.85 \\
\hline 137 & $26 S$ proteasome non-ATPase regulatory subunit 4 (29) & XP_002264558.1 & 2.95 \\
\hline 352 & 605 ribosomal protein L10a-1-like (29) & XP_002274218.2 & 2.73 \\
\hline 696 & 605 ribosomal protein L23-like (29) & XP_002285443.1 & 2.69 \\
\hline 213 & uncharacterized protein At2g37660, chloroplastic (m.: 29) & XP_002267965.1 & 2.55 \\
\hline 190 & elongation factor 2-like isoform 1 (29) & XP_002266780.1 & 2.40 \\
\hline 266 & 605 ribosomal protein L11-1-like (29) & XP_002270266.1 & 2.34 \\
\hline 303 & serine carboxypeptidase-like 18 (29) & XP_002272116.1 & 2.27 \\
\hline 604 & probable glutamate carboxypeptidase 2-like isoform $1(27,29)$ & XP_002283565.2 & 2.20 \\
\hline 57 & $\begin{array}{l}\text { hypothetical protein VITISV_003812 (60S acidic } \\
\text { ribosomal protein P0) (29) }\end{array}$ & CAN80537.1 & 2.16 \\
\hline 543 & heme-binding protein 2-like $(19,29)$ & XP_002281829.1 & 2.10 \\
\hline 538 & cucumisin-like (29) & XP_002281790.2 & -2.07 \\
\hline 559 & serine carboxypeptidase II-3-like (29) & XP_002282331.1 & -2.38 \\
\hline 572 & $\begin{array}{l}\text { ATP-dependent Clp protease proteolytic subunit 4, } \\
\text { chloroplastic (29) }\end{array}$ & XP_002282652.1 & -2.43 \\
\hline 169 & $60 S$ acidic ribosomal protein P2B isoform 1 (29) & XP_002266030.1 & -2.60 \\
\hline 2 & 40 S ribosomal protein SA (29) & A5BUU4.1 & -3.26 \\
\hline 501 & eukaryotic translation initiation factor 3 subunit M (29) & XP_002280247.1 & -4.72 \\
\hline 633 & $\begin{array}{l}\text { uncharacterized protein LOC100262703 } \\
\text { (dipeptidyl-peptidase 5) (29) }\end{array}$ & XP_002284264.1 & -4.78 \\
\hline 616 & ADP-ribosylation factor-like protein 5 (29) & XP_002283837.1 & -4.88 \\
\hline 702 & probable protein phosphatase 2C 60 (29) & XP_002285549.1 & -4.97 \\
\hline
\end{tabular}


Table 2 Proteins showing significant changes in responses to WS in the M4 genotype (Continued)

\begin{tabular}{|c|c|c|c|}
\hline n. & Name (f.c.) & Accession & $\Delta: W S / C$ \\
\hline 232 & protein transport protein SEC23-like (29) & XP_002268633.2 & -17.96 \\
\hline 518 & pyrrolidone-carboxylate peptidase isoform 4 (29) & XP_002280794.1 & d. \\
\hline 577 & subtilisin-like protease (29) & XP_002282841.1 & d. \\
\hline 578 & protein transport protein Sec24-like At3g07100-like (29) & XP_002282857.1 & d. \\
\hline 620 & aspartic proteinase nepenthesin-1-like (29) & XP_002283889.2 & d. \\
\hline \multicolumn{4}{|c|}{ Cell / signaling / development $(30,31,33)$} \\
\hline 114 & 70 kDa peptidyl-prolyl isomerase (31) & XP_002263566.2 & new \\
\hline 250 & $11 \mathrm{~S}$ globulin seed storage protein $2(28,33)$ & XP_002269868.1 & 50.05 \\
\hline 94 & peptidyl-prolyl cis-trans isomerase $\mathrm{H}(28,33)$ & XP_002262773.1 & 25.35 \\
\hline 490 & PRA1 family protein F2-like $(30,31)$ & XP_002279772.1 & 13.62 \\
\hline 741 & coatomer subunit gamma-2-like (31) & XP_003631645.1 & 5.84 \\
\hline 644 & glutelin type-A $1(28,33)$ & XP_002284459.1 & 5.53 \\
\hline 685 & probable plastid-lipid-associated protein 6, chloroplastic (31) & XP_002285326.1 & 2.21 \\
\hline 45 & $\begin{array}{l}\text { hypothetical protein VITISV_0120489 } \\
\text { (plastid lipid-associated protein) (31) }\end{array}$ & CAN69132.1 & 2.15 \\
\hline 391 & tubulin alpha chain (31) & XP_002275973.1 & -2.05 \\
\hline 503 & syntaxin-71 $(27,31)$ & XP_002280272.1 & -3.77 \\
\hline 459 & PITH domain-containing protein At3g04780 (33) & XP_002278320.1 & d. \\
\hline \multicolumn{4}{|c|}{ Transport (34) } \\
\hline 296 & V-type proton ATPase subunit H-like (34) & XP_002271887.1 & 5.21 \\
\hline 365 & V-type proton ATPase subunit E $(29,34)$ & XP_002274995.1 & 3.68 \\
\hline 358 & probable aquaporin PIP2-5 (34) & XP_002274555.1 & -3.94 \\
\hline \multicolumn{4}{|c|}{ Others $(15,18,23,24)$} \\
\hline 418 & ferritin-3, chloroplastic (15) & XP_002277114.1 & new \\
\hline 196 & selenium-binding protein 1 (15) & XP_002267004.1 & 10.44 \\
\hline 143 & soluble inorganic pyrophosphatase-like (23) & XP_002264695.2 & 2.20 \\
\hline 576 & nicotinate phosphoribosyltransferase-like $(18,23)$ & XP_002282786.1 & -6.86 \\
\hline 433 & probable carboxylesterase 15 (24) & XP_002277507.1 & -9.08 \\
\hline 332 & uracil phosphoribosyltransferase (23) & XP_002273489.1 & d. \\
\hline \multicolumn{4}{|c|}{ Hypothetical / Unknown function (35) } \\
\hline 108 & uncharacterized protein At5g48480 (35) & XP_002263284.1 & 20.80 \\
\hline 733 & probable nucleoredoxin 1-like (35) & XP_003631263.1 & 8.46 \\
\hline 582 & elicitor-responsive protein 3 (35) & XP_002282926.1 & 4.99 \\
\hline 80 & unnamed protein product (35) & CBI34823.3 & 4.73 \\
\hline 771 & uncharacterized protein LOC100854733 (35) & XP_003634361.1 & 3.22 \\
\hline 98 & $\begin{array}{l}\text { CBS domain-containing protein CBSX3, } \\
\text { mitochondrial isoform } 1 \text { (35) }\end{array}$ & XP_002262902.1 & 2.02 \\
\hline 580 & uncharacterized protein LOC100259086 (35) & XP_002282908.1 & -2.08 \\
\hline 281 & nodal modulator 1 (35) & XP_002271147.1 & -2.24 \\
\hline 443 & transmembrane protein 111 (35) & XP_002277989.1 & -2.43 \\
\hline 343 & uncharacterized protein LOC100242710 (35) & XP_002273917.1 & -3.60 \\
\hline 164 & $\begin{array}{l}\text { uncharacterized protein LOC100265424 } \\
\text { (D-alanine-D-alanine ligase family protein) (35) }\end{array}$ & XP_002265851.1 & -3.64 \\
\hline 335 & S-norcoclaurine synthase (35) & XP_002273566.1 & -4.27 \\
\hline 48 & hypothetical protein VITISV_002394 (35) & CAN70694.1 & -4.82 \\
\hline
\end{tabular}


Table 2 Proteins showing significant changes in responses to WS in the M4 genotype (Continued)

\begin{tabular}{llll}
\hline $\mathrm{n}$. & Name (f.c.) & Accession & \multicolumn{1}{c}{$\Delta$ :WS/C } \\
\hline 138 & non-lysosomal glucosylceramidase (35) & XP_002264575.2 & -5.50 \\
466 & clavaminate synthase-like protein At3g21360 (35) & XP_002278552.1 & -6.68 \\
40 & hypothetical protein VITISV_001156 (35) & CAN67361.1 & d. \\
547 & GDT1-like protein 4 (35) & XP_002281939.1 & $\mathrm{d}$. \\
\hline
\end{tabular}

Numbers reported in brackets refer to bin code (i.e. major functional categories). n.: identification number. f.c.: bin code of functional categories. Name: for proteins without a name in brackets are indicated the results from BLAST alignment against NCBI Viridiplantae database; m.: classification obtained through grape/ Arabidopsis or grape/potato matching by BLASTp algorithm (E.value $\left.<10^{-} 20\right)$. $\Delta$ : fold changes in WS plants with respect to the Control ones (up: \%(SI)WS/\%(SI)C, down: - \%(SI)C/\%(SI)WS). new: not present in C; .: disappeared, not present in WS

and dihydrolipoyllysine-residue acetyltransferase) reduced their abundance in WS in both genotypes, although the effect was more evident in 101.14. Moreover, only in M4, there was an increase in phosphoenolpyruvate carboxylase, which participates in replenishing TCA cycle intermediates [36].

Several enzymes of the TCA cycle were affected by WS (Fig. 3). In the 101.14 genotype, an ATP-citrate synthase and a fumarate hydratase increased in abundance, whilst a succinate dehydrogenase iron-sulfur subunit 1 disappeared. In M4, in addition to the same ATP-citrate synthase, an isocitrate dehydrogenase and a 2-oxoglutarate dehydrogenase also showed increases during water stress (Tables 1 and 2).

Among the proteins classified in carbon metabolism there was an aldehyde dehydrogenase family 7 member A1 that increased in abundance in WS in both genotypes (Tables 1 and 2). This protein was previously associated to the osmotic adaptation response to different abiotic stresses or ABA treatment [37, 38].

Only in M4 there was a surge in abundance of a succinate-semialdehyde dehydrogenase (acetylating) and a formate dehydrogenase (mitochondrial). The first of these is known to be involved in the metabolism of $\gamma$-aminobutyric acid (GABA) and plays a very important role in the response to reactive oxygen species (ROS), as suggested by the behaviour of the Arabidopsis ssadh mutant that accumulates elevated levels of $\mathrm{H}_{2} \mathrm{O}_{2}$ and is sensitive to UV-B light and heat stresses [37]. Similarly, an involvement of mitochondrial formate dehydrogenase under stress conditions, such as drought and cold, was previously suggested to be linked to the requirement to metabolize the increasing levels of formate and to use this alternative substrate to sustain the requirement for reducing power [39].

Among the proteins involved in lipid metabolism, a phospholipase D alpha 1 increased in WS in both genotypes. This enzyme, which produces phosphatidic acids hydrolyzing membrane glycerol-phospholipids, plays an important role in the responses that involve abscisic acid [40]. Many of the other changing proteins classified in this functional class, such as the carboxyl carrier protein of acetyl-CoA carboxylase-like, 3-oxoacyl-[acyl-carrier-protein] synthase
I and acyl-CoA-binding domain-containing protein 4-like isoform 1, which are involved in the metabolism of fatty acids, decreased in WS. Only in 101.14, glyoxysomal fatty acid beta-oxidation multifunctional protein MFP-a, involved in fatty acid degradation, showed a very large increase in abundance in WS (Table 1). In this unfavourable condition, 101.14 also induced a long chain acyl-CoA synthetase.

In both genotypes, WS negatively affected many proteins classified in the functional class of $\mathrm{N}$ and amino acid metabolism (Fig. 3). Nevertheless, the results revealed that the decrease in abundance of enzymes involved in amino acid (aspartate, serine, glycine, cysteine and aromatic amino acids) biosynthesis was more pronounced in 101.14. Moreover, only in M4 some of these proteins increased in abundance/appeared during WS. Among these was an arginase-like, known to be involved also in proline metabolism [41].

\section{Secondary metabolism and miscellaneous enzyme families}

Differences between the two genotypes were detected among the proteins classified in the secondary metabolism functional class (Tables 1 and 2; Fig. 4). In 101.14, 2-C-methyl-D-erythritol 2,4-cyclodiphosphate synthase, involved in the MEP/DOPX pathway [42], appeared in WS, whilst all the other changing proteins of this class decreased. However, in M4 a minor number of decreasing proteins was found, whereas six proteins involved in secondary metabolism rose or appeared in WS. Among these there were enzymes involved in the biosynthesis of flavonoids (chalcone-flavonone isomerase 1; anthocyanidin 5,3-O-glucosyltransferase) and stilbenes (stilbene synthase 1).

Many of the changing proteins classified in the miscellaneous enzyme families were identified as glutathione S-transferases (GST). Among these, only one was referred to the same form and decreased in both genotypes, while the other WS-affected GSTs were assigned to different entries. In M4, three GSTs increased and six decreased in WS. In 101.14 only three GSTs changed their levels. Among the proteins classified in the miscellaneous 


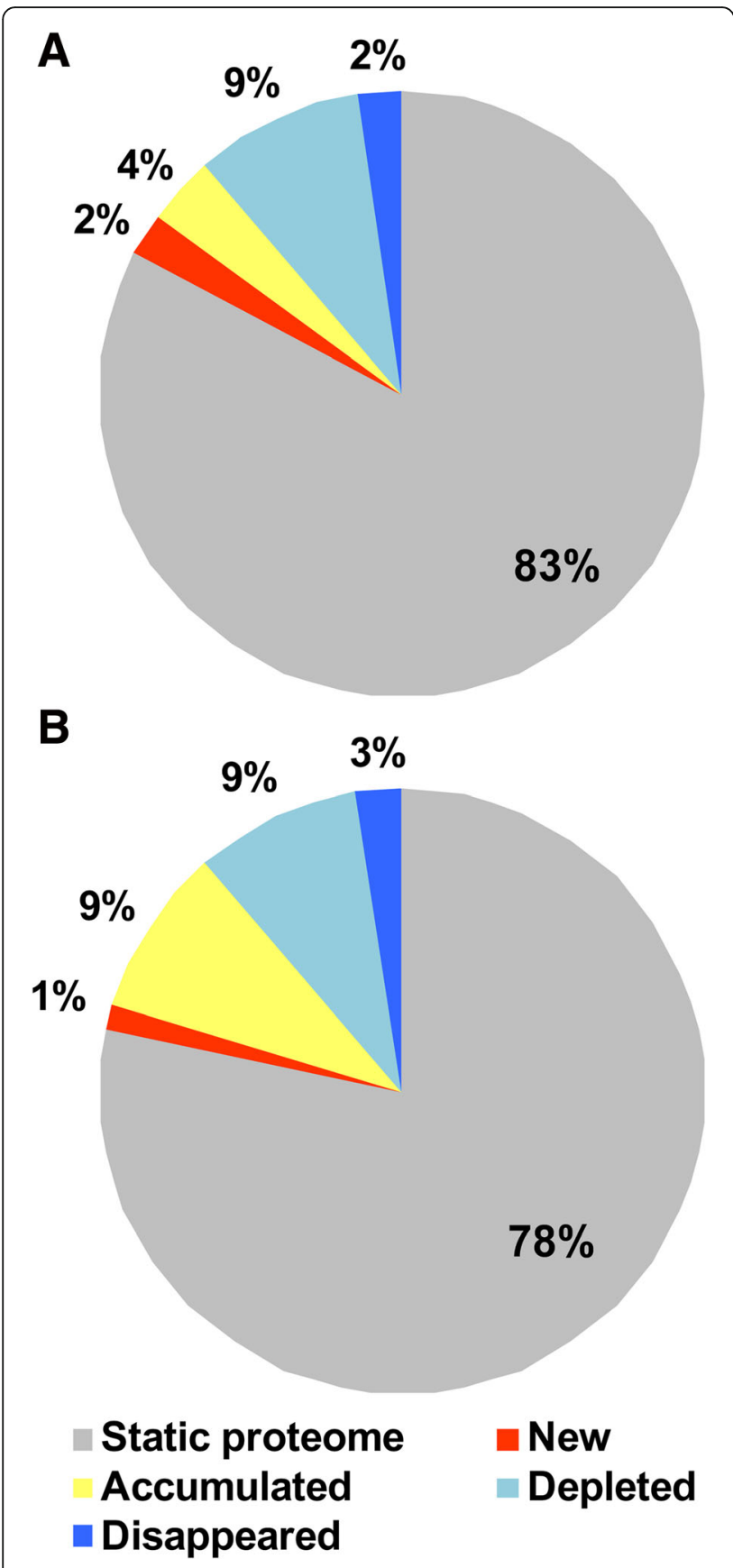

Fig. 1 Proteomic changes in response to water stress in 101.14 (a) and M4 (b) rootstock genotypes. Proteins that did not show an at least two-fold change between control and WS (Student's t-test; $p<0.05$ ) were classified as "static proteome". Proteins that significantly changed were divided into four groups: new, accumulated, depleted and disappeared

enzyme category that surged up in WS, a peroxidase 3 was found only in 101.14. Moreover, an NADP-dependent alkenal double bond reductase $\mathrm{P} 1$, which catalyzes the reduction of the $\alpha, \beta$-unsaturated bond of the reactive carbonyls, playing an important role in the antioxidative defence mechanisms [43], dropped in WS in 101.14, while in M4 the reduction was much lesser severe $(-4643 \%$ and $-238 \%$ in 101.14 and M4, respectively).

\section{Hormone and redox metabolisms}

A few proteins of which the levels varied in WS belong to the hormone metabolism functional class, especially in M4 (Tables 1 and 2; Fig. 4). Among the proteins that increased in both genotypes were the linoleate 13S-lipoxygenase $2-1$, involved in the biosynthesis of jasmonic acid [44] and the auxin-induced protein PCNT115 isoform 1. The extent of the observed changes was very different in the two genotypes: +155 and $+193 \%$ in 101.14 , and $+285 \%$ and $+1740 \%$ in M4 respectively. Nevertheless, only in 101.14 was there an increase in an isoform of auxin-repressed $12.5 \mathrm{kDa}$ protein as well as a decrease in indole-3-acetic acid-amido synthetase GH3.1. In both genotypes, WS negatively affected the abundance of the gibberellin 3-beta-dioxygenase and of the gibberellin 20 oxidase 3, both involved in gibberellin biosynthesis [45].

Only in 101.14, there was an increase in HVA22-like protein a, known to be induced by ABA under different abiotic stresses [46], while 1-aminocyclopropane-1-carboxylate oxidase 5 , an enzyme that catalyzes the last reaction of ethylene biosynthesis, disappeared.

Similarly, proteomic analysis revealed differences between the two genotypes concerning a few enzymes involved in the redox metabolism (Tables 1 and 2; Fig. 4). In detail, a peroxiredoxin-2E decreased to similar extent in both genotypes, whereas a catalase and a glutathione reductase increased in WS only in M4, and another catalase decreased in stress conditions only in 101.14. In this last genotype the glutathione S-transferase DHAR3, a chloroplastic enzyme involved in the scavenging of ROS [47], also increased.

\section{Nucleic acid and protein metabolisms}

Among the proteins relating to DNA/RNA functionalities, the basal transcription factor 3 (BFT3) rose in WS only in M4 (Tables 1 and 2). In this genotype an upturn in two proteins involved in RNA metabolism (DEAD-box ATP-dependent RNA helicase 37-like and DEAD-box ATP-dependent RNA helicase 56) also occurred. At the same time, the appearance of a ribonuclease 3 and of a proactivator polypeptide-like 1 isoform 1 occurred only in 101.14 (Tables 1 and 2).

In WS conditions, some proteins involved in protein synthesis or degradation significantly varied in abundance (Tables 1 and 2; Fig. 4). The results showed up the differences between the two genotypes. Among the proteins that increased, some ribosomal proteins (i.e., a $60 S$ ribosomal protein L10-1-like, a 605 ribosomal protein L11-1-like, a $60 \mathrm{~S}$ ribosomal protein L23-like and a $60 \mathrm{~S}$ 
A

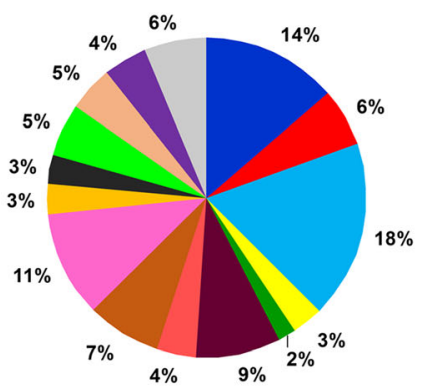

C

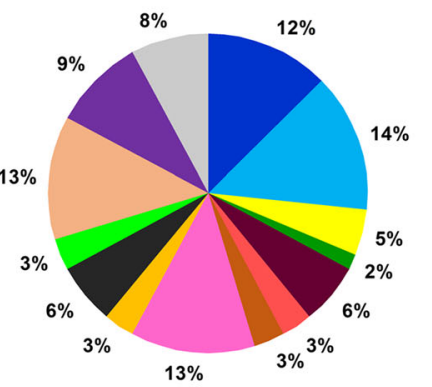

E

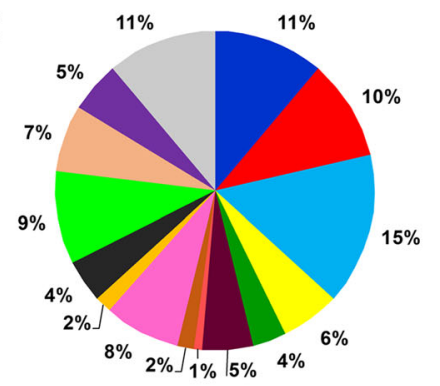

- Carbon and energy metabolism

Lipid metabolism

- Transport

= Redox

-Stress
- $\mathrm{N}$ and amino acid metabolism - Cell wall - DNA / RNA - Hormone metabolism - Others
B

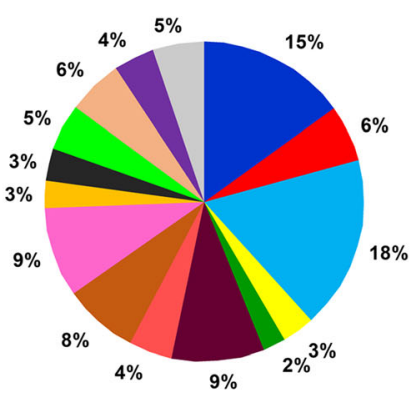

D

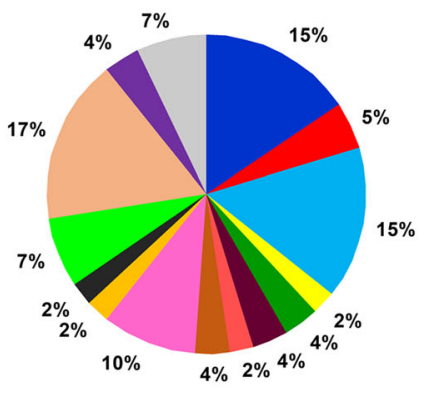

$\mathbf{F}$

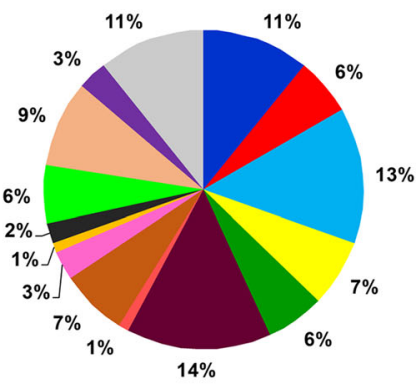

$=$ Protein

- Miscellaneous enzyme families

- Cell / signaling / development

$\backsim$ Secondary metabolism

Hypothetical / unknown function

Fig. 2 Functional distribution of identified proteins in the 101.14 (a, $\mathbf{c}$ and $\mathbf{e}$ ) and $\mathrm{M} 4$ ( $\mathbf{b}, \mathbf{d}$ and $\mathbf{f}$ ) rootstock genotypes. $\mathbf{a}$, b distribution of all the proteins identified in the control condition. $\mathbf{c}$ and $\mathbf{d}$ proteins that increased in abundance/appeared in WS. e and $\mathbf{f}$ proteins that decreased in abundance/disappeared in WS

acidic ribosomal protein P0), as well as the elongation factor 2-like isoform 1, were observed only in M4. Nevertheless, other proteins belonging to this functional class, such as the $60 \mathrm{~S}$ acidic ribosomal protein P2B isoform 1, the translation initiation factor 3 subunit $\mathrm{M}$ and the $40 \mathrm{~S}$ ribosomal protein SA, decreased in WS in this genotype. In 101.14, WS induced a rise in a $40 \mathrm{~S}$ ribosomal protein S15a-like isoform 2 and in the translation initiation factor 3 subunit E. In both genotypes, WS affected the abundance of proteins with diverse functions, from protein catabolism to protein maturation. Among these, in both genotypes there was an increase in $26 \mathrm{~S}$ proteasome non-ATPase regulatory subunits. Moreover, in 101.14 a $\mathrm{N}$-carbamoyl-L-amino acid hydrolase-like, a protease Do-like 1 chloroplastic-like, and an aspartic proteinase nepenthesin-1 increased, whereas in M4 an upturn of a serine carboxypeptidase-like 18 and a probable glutamate carboxypeptidase 2-like isoform 1 took place. Water stress negatively affected in both genotypes other enzymes with similar functions, such as aspartic proteinase nepenthesin1-like, pyrrolidone-carboxylate peptidase isoform 4, serine carboxypeptidase II-3-like, subtilisin-like protease-like and cucumisin-like. The same trend was observed for a protein transport protein SEC24-like, a subunit of COPII coat vesicles [48]. Only in 101.14, in WS four proteins, identified as a serine carboxypeptidase-like 18, two serine carboxypeptidase II-3-like and a serine carboxypeptidase-like 45-like, decreased. To these enzymes, which belong to a larger class of proteases in plants, both proteolytic and non-proteolytic functions have been attributed [49]. 


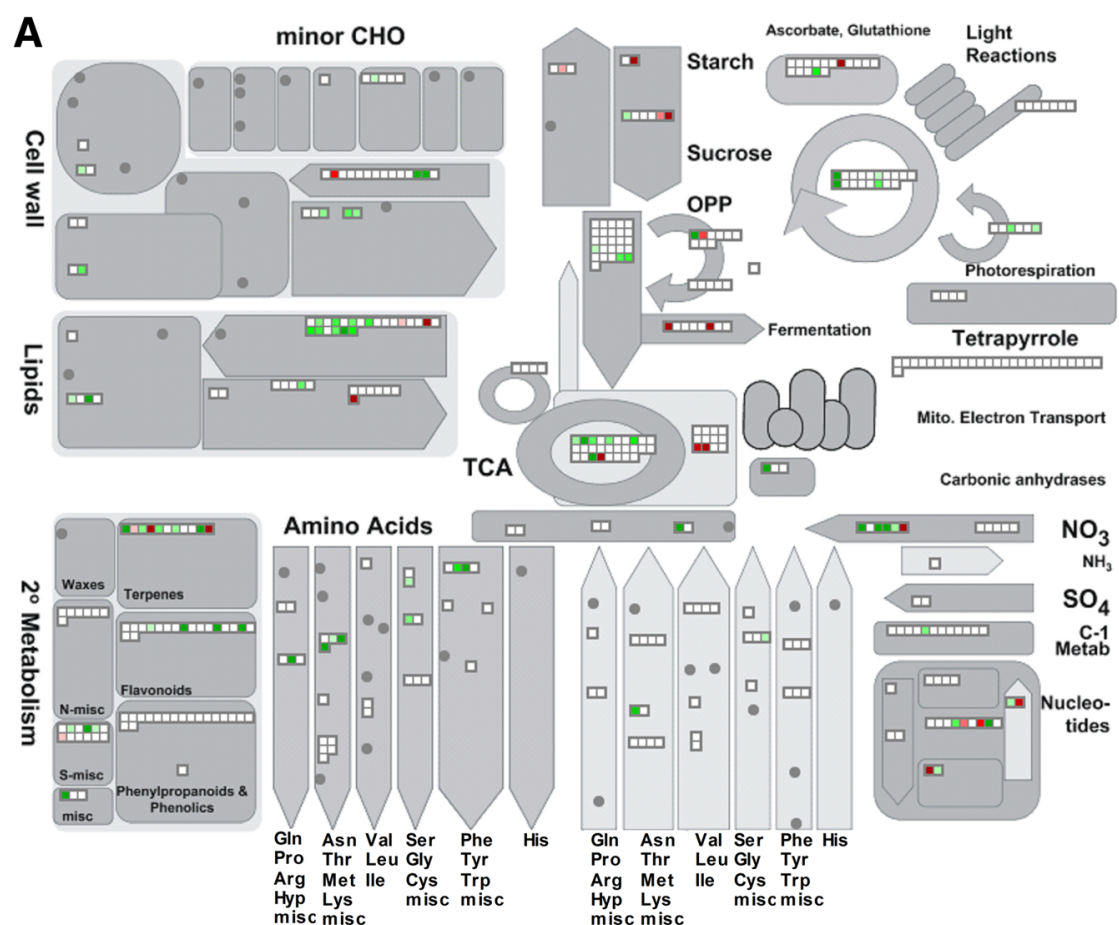

B minor $\mathrm{CHO}$

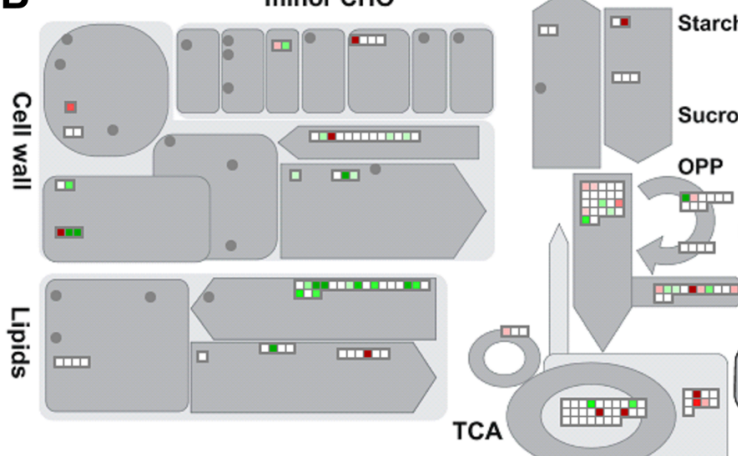
Ascorbate, Glutathione Light
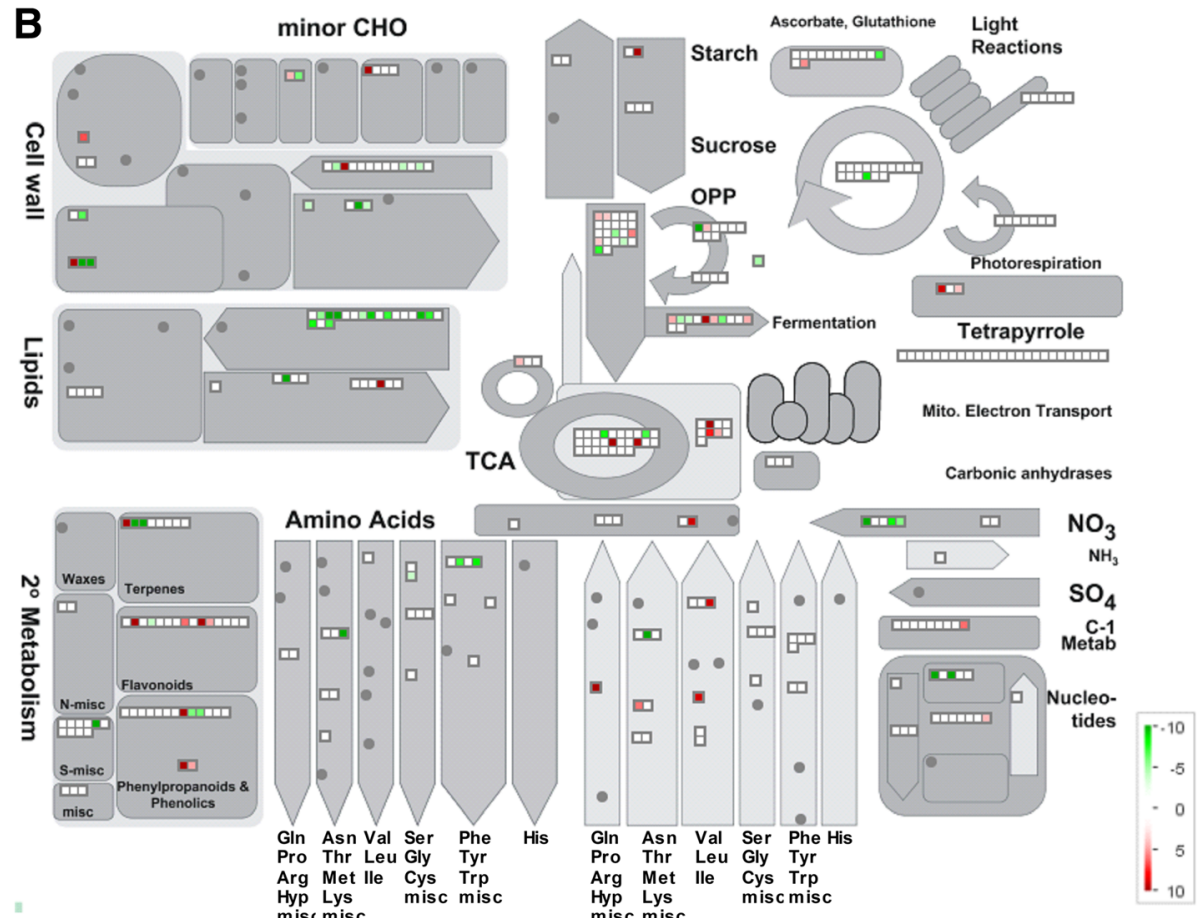

Fig. 3 MAPMAN overview of metabolic pathways in WS in root tissue of 101.14 (a) and M4 (b) rootstock genotypes. Green circles: decrease, white circles: no change, red circles: increase in protein abundance in WS respect to the control (see colour scale)

\section{Other cell functions}

Among the proteins belonging to the cell/signalling/ development functional classes (Tables 1 and 2), a $70 \mathrm{kDa}$ peptidyl-prolyl isomerase was identified. This protein, which appeared in WS in both genotypes, was previously described as changing its cellular localization under heat stress, according to its involvement in preserving cell functionality under abiotic stress [50]. The evident increase in the level of a peptidyl-prolyl cis-trans isomerase $\mathrm{H}$ taking place during WS was exclusive to M4. In 


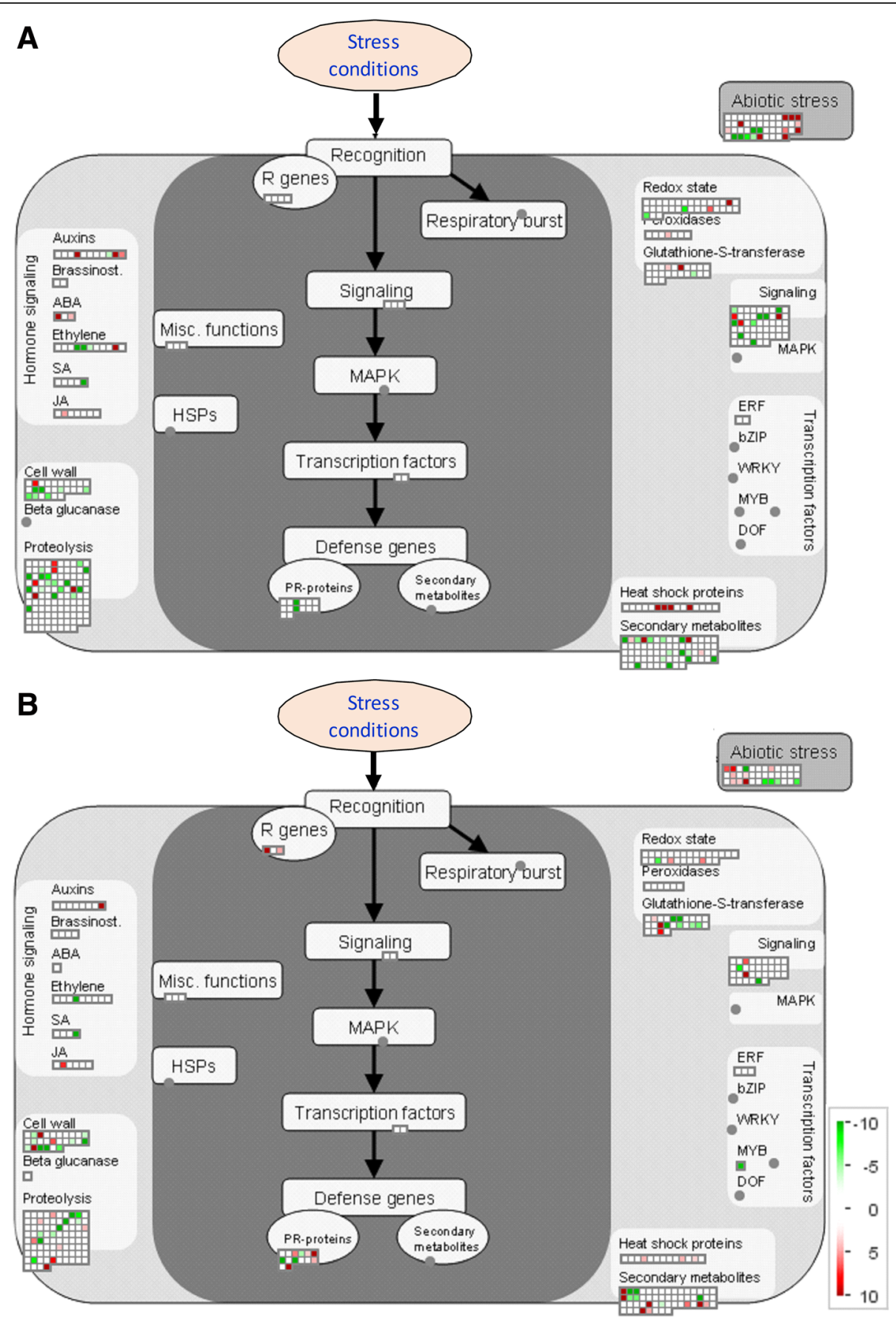

Fig. 4 MAPMAN overview of stress pathways in WS in root tissue of 101.14 (a) and M4 (b) rootstock genotypes. Green circles: decrease, white circles: no change, red circles: increase in protein abundance in WS respect to the control (see colour scale)

the same condition, only in 101.14 the appearance of a transmembrane emp24 domain-containing protein and the upsurge of a VAMP-like protein YKT61-like (both involved in vesicle-mediated transport) were observed. Interestingly, two proteins of the PRA1 protein family (small transmembrane proteins controlling vesicle trafficking; Kamei et al. [51]) showed a mirror behaviour in the two genotypes: one disappeared in 101.14 (PRA1 family protein B4-like) while the other increased in M4 (PRA1 family protein F2-like). Moreover, a coatomer subunit gamma-2-like, a COP protein involved in the ER/Golgi network [52], increased only in M4. By contrast, the coatomer subunit epsilon-1 isoform 1 decreased in 101.14. 
Water stress also affected a few cytoskeletal proteins (Tables 1 and 2). In particular, in 101.14 an actin-depolymerizing factor 10 was detected only in stressed roots, while in the same experimental condition a tubulin beta-1 chain isoform 1 decreased. Moreover, a tubulin alpha chain decreased in M4.

Water stress also affected the abundance of a few storage proteins (Tables 1 and 2). In detail, an upturn of a glutelin type-A 1 occurred in both genotypes, while only in M4 there was a consistent rise of an $11 \mathrm{~S}$ globulin seed storage protein 2. Aquaporin TIP2.3 and PIP2-5 decreased in abundance in 101.14 and M4, respectively.

Among the proteins belonging to the transport functional class (Tables 1 and 2), WS induced in 101.14 the increase of a pyrophosphate-energized vacuolar membrane proton pump 1, whereas two subunits (H-like and E) of the V-type proton ATPase were positively affected by WS in M4.

\section{Proteins involved in stress responses}

Water stress affected the abundance of 17 and 23 proteins belonging to the stress functional class in 101.14 and M4, respectively (Tables 1 and 2; Fig. 4). Some of these were identified as germin-like proteins (GLP), a group of proteins with heterogeneous functions belonging to the cupin superfamily known to change their levels in different biotic and abiotic stress conditions [53]. In both genotypes, two GLPs were positively affected by WS, while the other ones were found to decrease in this adverse condition, though to a major extent in 101.14.

Similar considerations also applied to both the stress-related and the major latex protein (MLP) like proteins. Although further work is necessary to clarify the specific function(s) of MLPs, emerging evidence suggests their role in improving the tolerance to stress conditions [54-56]. In detail, in 101.14 the rise of two stress-related protein-like and of two MLP-like proteins was observed. In M4 the same stress-related protein-like and MLP-like protein 34 appeared, and two other MLP-like proteins increased in abundance.

Two osmotin like-proteins, which play an important role in osmotic adjustment to tolerate WS conditions [57, 58], rose in abundance in WS only in M4. In the same genotype, WS also positively affected a disease resistance response protein 206, a chitinase class I basic, a basic endochitinase, an endoplasmin homolog, a topless-related protein 4-like isoform 1, and a pathogen-related protein. Nevertheless, only in 101.14, WS induced the appearance or a great increase in three heat-shock proteins.

\section{Metabolic analysis}

The changes of metabolite contents induced by WS are visualized in Fig. 5. Many metabolites appeared to be

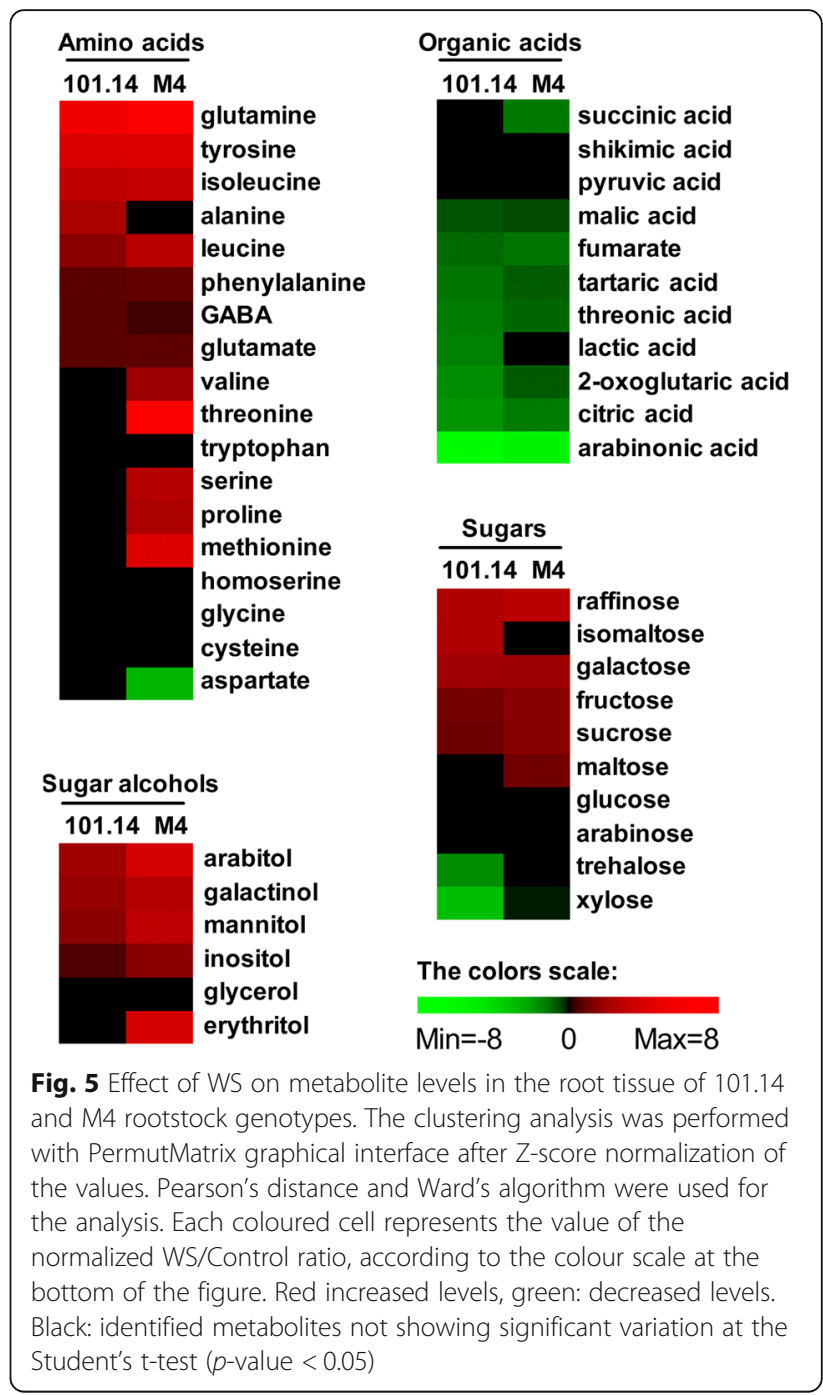

affected by the stress condition. Overall, amino acids, sugars and sugar alcohols were positively affected by WS, whilst almost all organic acids decreased under the unfavourable condition. Some of the changes were different in the two genotypes.

The analysis revealed in both genotypes a quite similar increasing trend, during WS, for some sugars, such as raffinose, galactose, fructose and sucrose. The increase of the last two metabolites was higher in M4. However, WS induced a greater increase in maltose in M4 and higher levels of iso-maltose in 101.14.

WS raised the levels of some sugar alcohols, such as inositol, galactol, mannitol and arabitol in both genotypes, but they increased to a higher extent in M4. Moreover, an upturn of erythritol occurred only in this last genotype.

Under WS, the levels of many metabolites of the Krebs cycle were negatively affected in both genotypes 
while, among the amino acids, similar increases in tyrosine, isoleucine, phenylalanine glutamine and glutamate took place. However, a greater increase in leucine was observed in M4. Only in 101.14 was an upsurge of alanine detected, whereas particular increments in valine, serine, methionine, threonine, and proline were measured in M4. Under WS, an increase of GABA level occurred in both genotypes, but to a major extent in 101.14.

\section{Discussion}

According to previous studies conducted in the same experimental conditions [29, 30], proteomic analysis strengthens the crucial role of roots in the plant responses to water stress (WS) and allows some particular traits of WS tolerance in a perennial plant species such as grapevine to come to light. The physiological measurements previously performed by Meggio and co-workers, revealed different capabilities of 101.14 and M4 rootstock genotypes to sustain $\mathrm{CO}_{2}$ assimilation rate $(\mathrm{A} n)$ and stomatal conductance $\left(\mathrm{g}_{\mathrm{s}}\right)$ [29]. In both genotypes there occurred a progressive decrease of $g_{s}$ and $A n$ during the first days of stress, while afterwards 101.14 showed a further decrease whereas M4 partially recovered to 20 and $40 \%$ of the control condition for $\mathrm{g}_{\mathrm{s}}$ and $\mathrm{A} n$, respectively. This anisohydric behaviour also appeared linked to a better ability of roots to sustain loss of water [29]. When the field capacity was reduced to $30 \%$, the roots of M4 showed, indeed, a greater capacity to adjust its osmolality adequately as well as to maintain cell integrity, as suggested by the protein and ion contents and by the recovery observed after re-watering [29].

The present work shows that the water-limiting condition induced significant changes in the whole root proteome (i.e., 17 and $22 \%$ of the quantified proteins in 101.14 and M4, respectively) and this result appeared to be well related to the capability of the genotype to respond more (M4) or less (101.14) positively to this stress condition. Whereas the functional distribution of the identified proteins in the control condition was quite similar in the two genotypes, important differences were found among the proteins that changed in WS (Fig. 2). The differences observed between the two genotypes were also consistent with the trends of the main metabolites (Fig. 5). Taken together, M4 showed positive metabolic responses potentially able to counteract the WS effects, whilst in 101.14 the suffering status of the roots became evident.

\section{Root growth and osmotic adjustment}

An important feature observed in plants exposed to water-limiting conditions is their ability to maintain primary root elongation, a process that is strictly dependent on several different responses. Crucial aspects for sustaining cell growth are to guarantee an adequate cell wall extensibility as well as to maintain water uptake, which depends heavily on an adjustment of the solute potential $[28,59]$.

Proteomic analysis showed that WS induced in both genotypes changes in abundance of some proteins involved in the biosynthesis and expansion of cell walls, as well as higher levels of typical osmoprotective compounds (i.e., amino acids, raffinose and some sugar alcohols). M4 showed a better capability to respond to the adverse condition, as indicated by the increase in specific proteins involved in cell wall loosening (i.e. xyloglucan endotransglucosylase/hydrolase protein B). Moreover, even if both genotypes showed an increase in compatible solutes, this response was greater in M4, as suggested by the increased levels of proline and of many sugar alcohols. Recently, the physiological relevance of this last class of compounds in the response to WS was investigated in fruit and leaves of grapevine, where WS induced the synthesis of these osmoprotective solutes, especially in the fruit mesocarp [60]. Our study shows that WS also evoked the synthesis of some polyols, such as mannitol, inositol, galactinol, and erythritol, in the roots. Overall, the higher polyol levels detected in the tolerant genotype M4 confirmed the importance of these compounds in improving WS response suggested by previous works $[60,61]$. Furthermore, other metabolites, such as amino acids, appeared to contribute to the osmotic adjustment evoked by WS with a more massive response in M4 (see below). In addition, it is interesting to observe that only in M4 was there found an increase in two osmotin like-proteins, a class of proteins previously found to increase WS tolerance [57, 58]. Taken together, our study highlights a greater capability of M4 to activate molecular and biochemical processes useful to sustain the osmotic adjustment needed for root growth in a very severe WS condition.

Even though previous works pointed out the central role of aquaporins in the water stress response, the present study found decreases of aquaporin TIP2-3 and PIP2-5 in 101.14 and M4, respectively. This ostensible discrepancy could be explained by observing that our study analysed the whole root organ, while the water channel play an important role only in the young roots $[19,24,62]$. At the same time, we should consider that these proteins show diurnal changes in expression [62]. The proteomic analysis was performed on roots sampled $2 \mathrm{~h}$ after the start of the light period, a moment in which the daily increase of aquaporins may not yet be evident. Nevertheless, in woody root systems, the older suberized root portion can contribute significantly to water uptake and this role could depend upon the suberisation process occurring in this part of the root organ [24]. Proteomic analysis highlighted that only in 101.14 was there found an increase of a long chain acyl-CoA synthetase, an enzyme involved in suberin biosynthesis [63]. 


\section{Root growth and hormones}

Hormones have a central role in the plant responses to environmental stimuli. Beyond ABA, which plays a substantial role in water stress, other hormones such as auxin, gibberellins (GAs) and jasmonate (JA) are involved in the responses to this abiotic stress ([64] and references therein). Our analysis revealed changes in the abundance of proteins involved in hormone metabolism, which overall suggests a decrease in GAs biosynthesis and an increase in that of JA in both genotypes under stress. These possible changes appear consistent with the reduction in root growth and with the typical responses to stress conditions $[65,66]$. Moreover, the proteomic analysis revealed an increase in abundance of an auxin-induced protein PCNT115 isoform 1, which was considerably higher in M4 than in 101.14. This result fits well with the concomitant appearance of an auxin-repressed $12.5 \mathrm{kDa}$ protein and the decrease in an indole-3-acetic acid-amido synthase GH3.1 that occurred only in 101.14. Recently, a central role of auxin-induced protein PCNT115 in the formation of new adventitious roots in chrysanthemum cuttings was proposed [67]. This finding sustains the idea that this protein could play the same role in the root of the grapevine plant.

\section{Carbohydrate metabolism and plastidial functionality}

Water stress deeply affected carbohydrate metabolism: a higher abundance of enzymes involved in the pathways of starch breakdown and sucrose synthesis was observed. This greater use of root storage starch could be a consequence of the reduction of sugar provision from the leaf organ, a result of the fall in net $\mathrm{CO}_{2}$ assimilation previously described by Meggio et al. [29]. Nevertheless, these changes at the root level were more evident in M4, even while this genotype maintained photosynthetic activity under more severe WS conditions [29]. Previously, Regier and co-workers found that a crucial characteristic of Poli, a black poplar clone tolerant to WS, was its capability to maintain the photosynthetic rate as well as to improve adequately the usage of carbon skeletons in the root [27]. In agreement with these results, M4 showed a similar behaviour in response to WS.

Nonphotosynthetic plastids are the sites of primary pathways, such as those involved in the synthesis of starch and fatty acids and in nitrogen assimilation [68]. Proteomic analysis suggests a clear reduction in these processes in WS. Some of the plastidial enzymes involved in the production of reducing power (i.e., glucose-6-phosphate 1-dehydrogenase and ferredoxin-NADP reductase) or in plastidial glycolysis (i.e., triosephosphate isomerase and enolase) decreased in abundance in both genotypes. Moreover, some enzymes involved in nitrogen assimilation (i.e., ferredoxin-nitrite reductase and glutamine synthetase in 101.14 and M4, respectively) also decreased in WS.
In WS, a parallel reduction in the abundance of several enzymes involved in fatty acid biosynthesis occurred. Although this effect was observed in both genotypes, the concomitant increase of the glyoxysomal fatty acid beta-oxidation multifunctional protein MFP-a, evident only in 101.14, may suggest that in this genotype lipid catabolism was higher than in M4, possibly due to a different strategy to sustain energetic requirements (i.e., lipid respiration).

Taken together, these data are consistent with a reduction in plastidial functionality that could be directly due to a reduction in abundance of specific enzymes while at the same time there could be an inability to sustain the demand for reducing power by the anabolic processes [68]. According with a shift in the metabolic ways of sustaining the request of NADPH, an increase in cytosolic glucose-6-phosphate dehydrogenase occurred in both genotypes.

\section{Mitochondrial functionality}

Proteomic analysis revealed severe changes in mitochondrial functionality. Indeed, WS induced a fall of the intermediates of the tricarboxylic acid (TCA) cycle in both genotypes. At the same time, a few enzymes of this pathway, such as ATP-citrate synthase and a fumarate hydratase, increased in abundance, while others, such as components of the pyruvate dehydrogenase complex, were adversely affected by WS. This last effect was more evident in 101.14, where many of the components of this enzyme complex decreased under the stress. Conversely, only in M4, other enzymes of the TCA cycle, such as isocitrate dehydrogenase and 2-oxoglutarate dehydrogenase, as well as the anaplerotic enzyme PEP carboxylase, increased in WS, suggesting that this genotype was generally able to maintain a better functionality of the TCA cycle in WS. According to other work [39], this hypothesis also seems to be supported by the increase in mitochondrial formate dehydrogenase observed in M4.

Under stress conditions, a concomitant increase in the levels of several amino acids occurred. This result fits well with the central role of the TCA cycle in providing carbon skeletons for amino acid biosynthesis [69]. Indeed, it could be observed that the higher activation of the TCA cycle hypothesized in M4 is associated with a higher accumulation of specific amino acids, such as valine, threonine, serine, proline, and methionine. Nevertheless, WS negatively affected a larger number of enzymes involved in amino acid metabolism in 101.14 than in M4. In this view, it may be considered that the increase in amino acid levels detected in the stress condition could be, at least partly, a consequence of an increase in protein degradation. This event could be ascribable to general cell damage and/or could represent a specific response 
evoked by the requirement for alternative substrates for respiration $[70,71]$.

Although the energy demand is expected to decrease as a consequence of a reduction in root growth and ion uptake, two events frequently affected when WS becomes severe, the maintenance of an adequate mitochondrial respiration is fundamental to sustain the cell functionality ([72] and references therein). Our study reveals that a deficiency in respiratory substrates could occur and, at the same time, only in 101.14 the mitochondrial electron chain (i.e., disappearance of the succinate dehydrogenase [ubiquinone] iron-sulfur subunit 1 , mitochondrial) was negatively affected by WS. Overall, the data suggest that, whereas in 101.14 a reduction in the functionality of respiratory machinery emerged, M4 showed a better capability for sustaining the demand for energy.

\section{Protein metabolism}

Changes in both protein catabolism (i.e., increase in abundance of regulatory proteins of the $26 \mathrm{~S}$ proteasome and of proteases) and synthesis (i.e., changes in abundance of ribosomal proteins and of translation factors) occurred. Nevertheless, the changes in other proteins, such as transport protein SEC24-like, proteins belonging to PRA1 family, coatomer subunits, proteases and other ribosomal proteins, highlighted the occurrence of broad changes in overall protein metabolism. Moreover, only in M4, an increase in basal transcription factor 3 (BFT3), involved in transcription initiation, translational regulation and protein localization and known to be modulated under stress conditions ([73] and references therein), was found. Taken together, the results suggest that in 101.14, protein catabolism prevails, whereas M4 is characterized by a prevalence of protein synthesis and by a greater capability to maintain the vesicle traffic functionality. In this view, a very interesting difference between the two genotypes is the higher number of ribosomal proteins identified and positively affected by WS in M4. This result encourages further studies to deepen knowledge about the changes induced by WS in the cytosolic ribosomal proteome(s) under both the quantitative and the qualitative points of view ([74] and references therein).

\section{Secondary metabolism and oxidative stress responses}

Many differences between the two genotypes concerned proteins involved in secondary metabolism. The main result consisted in an increase of enzymes involved in the synthesis of flavonoid and stilbene compounds, which occurred only in M4. These data are in agreement with the previous transcriptomic study on 101.14 and M4 genotypes grown in the same WS experimental conditions, contributing to reinforce the conclusion that the capability to synthesize larger amounts of antioxidant compounds, such as flavonoids and stilbenes (i.e. resveratrol), enhances the tolerance to WS in M4 [30]. Furthermore, it is interesting to observe that only in M4 was there found an increase of typical ROS scavenging enzymes, such as catalase and glutathione reductase. In other words, the greater tolerance of this genotype appears also to be linked to the ability to activate mechanisms capable of better counteracting the oxidative stress occurring in WS conditions [17, 26, 30, 75].

\section{Stress-related proteins}

Water stress induced changes in several stress-related proteins that were quite different in the two genotypes. M4, when compared to 101.14, showed a larger number of stress-related proteins belonging to Bet v I family, such as MLP proteins that increased in WS. The possible role played by these proteins, in the response to abiotic and biotic stresses is emerging [55, 76-78]. For example, the central role of MLP43 in the modulation of the ABA response to drought conditions has been recently highlighted [55]. Although further work is necessary, it may be hypothesized that the higher tolerance of M4 to WS is also related to the presence of specific MLP-like proteins.

Moreover, the rise of chitinases in the root observed under drought was related to a response useful to reduce the risk of infection in drought-weakened plants. [79, 80]. Our study shows an increase in two chitinases only in the M4 genotype.

Almost all of the stress-related proteins of the germin subfamily decreased in WS in both genotypes. Further work is needed to explain this result, considering that GLPs are a very heterogeneous class whose members show very different characteristics, such as oxalate oxidase activity, superoxide dismutase activity and other unclarified roles involved in the photoperiodic and abiotic stress responses [81, 82].

As previously observed in typical stress conditions [83], an increase in a few heat-shock proteins occurred in both genotypes. The changes observed in 101.14 and in M4 involved different members of this protein family, reaffirming peculiarities in the strategy and/or different abilities of each genotype to respond to WS conditions. Moreover, it is interesting to observe that the three small heat-shock proteins (sHSPs) which appeared or dramatically increased in the 101.14 genotype have a Hsp20/ $\alpha$-crystallin domain, which characterized some sHSPs strongly induced by heat and oxidative stress [84].

\section{Conclusion}

This study provides new information about the responses to WS in soil growth conditions of the roots of a woody plant, i.e., grapevine. Comparative analysis of two genotypes with different tolerance to this abiotic stress 
highlighted specific traits of the strategy adopted to counteract it (Fig. 6). The proteomic/metabolomic analyses strengthen the view that a crucial aspect is the capability to activate and to sustain the metabolic pathways involved in the protection of the cell from hazardous events, like a drop in cell turgor, increased oxidative stress and loss of cell structural integrity. Within this framework, the root has to sustain metabolic activities in a condition of reduced carbon skeleton availability, which derives from the reduction in plant photosynthetic performance. In other words, the root must optimize the availability of metabolic energy and sustain as much as possible root functionality and growth. A crucial aspect in the modulation of root responses is the hormonal balance, which controls these physiological/biochemical processes.

An important aspect emerging from this study is that the responses of the root to WS depend on its ability to guarantee mitochondrial functionality, essential for both respiration and anabolic processes. In this view, the activation of alternative pathways capable of sustaining the TCA cycle and the production of reducing power appear to be distinctive responses of the tolerant genotype.
Moreover, the observed increases in several stress-related proteins, somewhat different in the two genotypes studied, confirm the multifaceted and very important role of these proteins in the responses to WS.

\section{Methods}

Root material and water-deficit treatment

Two-year-old grapevines (genus Vitis) of rootstocks 101.14 Millardet et de Grasset (V. riparia x $V$. rupestris) and M4 $[(V$. vinifera $\times \mathrm{V}$. berlandieri $) \times \mathrm{V}$. berlandieri $\mathrm{cv}$. Resseguier no. 1] were grown in pots filled with a sand-peat mixture (7:3 in volume) using experimental conditions previously described by Meggio and co-workers [29].

Plants of each genotype ( 3 plants for each replicate) used as control (C) were maintained at $80 \%$ of soil field capacity while in pots of plants subjected to water stress (WS) the water supply was progressively reduced until down to $30 \%$ of field capacity. In order to maintain the established soil water content (SWC), an adequate quantity of water was added twice a day, at 8:00 h and at 18:00 h. After 10 days, starting at 9:00 h $(2 \mathrm{~h}$ after the start of the light period), plants were sampled immediately after in vivo

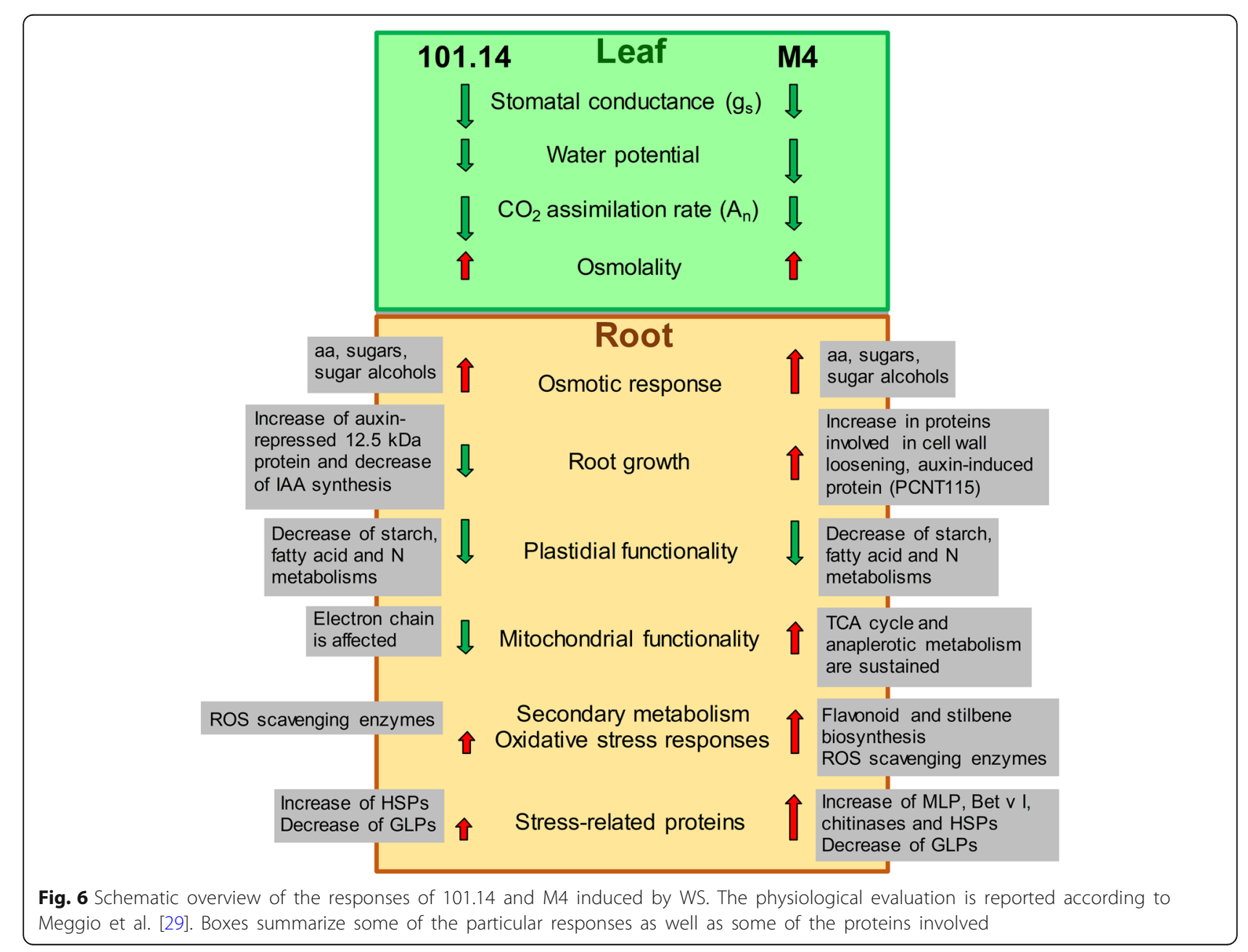


measurements [29]. Root samples were obtained harvesting the whole root system. The soil was removed from roots by a gentle shaking action. After that, the whole root system was rinsed twice in distilled water, immediately blotted with paper towels, weighed and then frozen in liquid nitrogen and stored at $-80{ }^{\circ} \mathrm{C}$ until use.

\section{Protein extraction}

Frozen powdered samples (1 g) of four replicates for each experimental conditions were finely powdered in liquid nitrogen using a pestle and mortar, then to each was added $5 \%(\mathrm{w} / \mathrm{w})$ of polyvinylpolypyrrolidone, and the total protein fraction was extracted as described by Prinsi et al. [85]. Protein samples were then dissolved in SDS-buffer $[150 \mathrm{mM}$ Tris-HCl pH 6.8, 10\% (w/w) glycerol, 2\% (w/w) Sodium Dodecyl Sulphate (SDS), 2\% (v/v) 2-mercaptoethanol] and incubated at $95{ }^{\circ} \mathrm{C}$ for $5 \mathrm{~min}$. The sample was centrifuged at $10,000 \mathrm{~g}$ for $10 \mathrm{~min}$ and the supernatant stored at $-80{ }^{\circ} \mathrm{C}$ until further use. The protein concentration was determined by the 2-D Quant Kit (GE Healthcare).

\section{One-Dimensional Gel Electrophoresis (1-DE) and tryptic digestion}

The SDS-PAGE (SDS - PolyAcrylamide Gel Electrophoresis) was performed as described by Laemmli [86] in a Hoefer ${ }^{\text {ra }}$ SE 600 Ruby Vertical system. Each protein sample, was purified in $10 \%$ acrylamide gel $(10 \% \mathrm{~T}, 2.6 \% \mathrm{C}, 180 \times 160 \times 1 \mathrm{~mm})$. Analytical running was conducted at $200 \mathrm{~V}$ at $20{ }^{\circ} \mathrm{C}$ until the bromophenol blue line ran off. Proteins were stained using the colloidal Coomassie Brilliant Blue G-250 procedure, as previously described by Neuhoff and co-workers [87]. Electrophoresis was monitored using the Full-Range Rainbow Markers (Mr 12,000-225,000) (GE Healthcare).

The blank portions of the gels as well as the regions above $150 \mathrm{KDa}$ or below $12 \mathrm{KDa}$ were removed from the gel, obtaining a line of about $12 \mathrm{~cm}$ for each sample. Then each line was cut in 15 regular slices (8x10x1 $\mathrm{mm})$. In the further analysis each slice was treated as an independent sample. In-gel digestion of the slices was performed according to Prinsi and co-workers [88] with the only refinements consisting in the additionally cutting of the slice into 8 portions and in the volume adjustment, in order to assure that the gel pieces were completely immersed in the treatment solutions. The extracted peptides were finally dissolved in $10 \mu \mathrm{l}$ of $0.1 \%(\mathrm{v} / \mathrm{v})$ of formic acid (FA).

\section{Protein mass spectrometry analysis}

All mass spectrometry experiments were conducted on an Agilent 6520 Q-TOF mass spectrometer equipped with an HPLC Chip Cube source driven by a 1200 series nano/ capillary LC system (Agilent Technologies). Both systems were controlled by MassHunter Workstation Acquisition (version B.02.01, B2116.20; Agilent Technologies). The chip consisted of a 40-nL trap column and a $75 \mu \mathrm{m} \times$ 150-mm analytical column (Zorbax SB, C18, $300 \AA$ ). Peptides were loaded onto the trap column at $4 \mu \mathrm{L} \mathrm{min}{ }^{-1}$ in $5 \%(\mathrm{v} / \mathrm{v})$ acetonitrile and $0.1 \%(\mathrm{v} / \mathrm{v})$ FA. The chip was then switched to separation, and peptides were eluted into the mass spectrometer during a 43-min acetonitrile gradient (from 5 to $50 \% \mathrm{v} / \mathrm{v})$ in $0.1 \%(\mathrm{v} / \mathrm{v})$ FA at $0.4 \mu \mathrm{min}^{-1}$. The mass spectrometer ran in positive ion mode and MS scans were acquired over a range from 300 to 3000 mass-to-charge ratio $(\mathrm{m} / \mathrm{z})$ at 4 spectra $\mathrm{s}^{-1}$. Precursor ions were selected for auto-MS/MS with a maximum of 4 precursors per cycle and active exclusion set at 2 spectra and released after $0.1 \mathrm{~min}$.

Analysis of MS/MS spectra were performed by Spectrum Mill MS Proteomics Workbench (Rev A.03.03.084; Agilent Technologies). Carbamidomethylation of cysteines was set as fixed modification while variable modification was oxidation of methionines. Trypsin was selected as enzyme for digestion, accepting 2 missed cleavages per peptide. The search was conducted against the subset of Vitis vinifera protein sequences (77,487 entries) downloaded from the National Center for Biotechnology Information (http://www.ncbi.nlm.nih.gov/). The database was concatenated with the reverse one. The threshold used for peptide identification was Spectrum Mill score $\geq 9$, SPI\% $\geq 70 \%$, difference between forward and reverse scores $\geq 2$ and error mass shift comprised between $\pm 10 \mathrm{ppm}$. Peptide quantification was obtained as the Spectrum Intensity (SI) of the precursor $\left(\mathrm{MH}^{+}\right)$. Protein quantification was obtained summing the SI of all identified peptides and normalized as the \% respect the sum of all validated proteins in the sample $(\%(\mathrm{SI})$, summing all valid peptides in the 15 slices of each lane). Obviously, within each sample some redundant entries were found. If one entry was repeated in two vertically adjacent slices, the two single quantifications were summed to reduce the interference of the cut procedure. In all other cases, the entries were treated as independent form of the same protein (among them, only forms representing at least the 80\% of the total protein were considered for quantitative purposes). Only proteins showing at least a two-fold change in their \%(SI) (Student's t-test, $p<0.05$ ) were considered subjected to a significant change in abundance.

\section{MapMan visualization}

The proteomic data were visualized in figures reporting schematic metabolism pathways that were produced using the MapMan software [34]. The MapMan software (Version 3.6.0RC1) for local application was downloaded from http://mapman.gabipd.org/ Web Site. Mapping file, kindly provided by Živa Ramšak (see acknowledgement), was prepared starting from Vitis vinifera protein sequences 
present in NCBI and using the BLASTp algorithm to match grapevine proteins with Arabidopsis and potato ones. The matching grape/Arabidopsis or grape/potato were kept only if E-value of the BLASTp match was lower than $10^{-20}$. When a grapevine sequence did not have any hits in either TAIR9 or potato ITAG, then it was automatically placed into 35.2 (not assigned/unknown).

\section{Metabolite analysis}

Metabolites were extracted considering the polar fraction derived from $150 \mathrm{mg}$ of frozen powder, according to the protocol by Lisec and coworkers [89] with some modifications, as previously described [90]. The analyses were performed on three replicates through a GC-MS approach using the instrument comprising the gas chromatograph 7890 and the single-quadrupole spectrometer 5975 (Agilent Technologies).

Chromatograms and spectra were evaluated through the software MetaboliteDetector version 2.0.6 beta [91]. After the conversion of Agilent D files to netCDF, the chromatograms were aligned according to the elution of the C8-C40 Alcane Mixture and compound spectra were isolated through deconvolution [peak threshold: 10; minimum peak height: 2 , number of bins per scan: 10 ; deconvolution width (scans): 8.0]. Metabolites were identified matching spectral and retention index (RI) information to a library containing information about the entries of the GMD 20111121VAR5 ALK MSL provided by the Golm Metabolome Database [92], setting the cutoff score to 0.90 and the max RI difference to 15 . Identified metabolites were quantified integrating the peak area of the ions normalized by the one of ribitol.

Sucrose level was estimated by colorimetric procedure. Briefly, sucrose was extracted as previously described in Prinsi et al. [88] and then estimated from the difference between total and reducing sugars that were determined according to Nelson method [93].

Student's t-test ( $p$-value $<0.05)$ was performed through Statistica software v 8.0 (StatSoft Inc., Tulsa) to determine significant differences between means of stressed and well-watered samples.

The results were visualized through the two-way hierarchical clustering methodology using the software PermutMatrix [94, 95]. For this purpose, the data were converted into a binary matrix replacing the values that did not show significant differences by zero. Pearson's distance and Ward's algorithm were used for the analysis.

\section{Additional files}

Additional file 1: Table S1. Technical parameters concerning peptide validation and protein identification. (PDF $133 \mathrm{~kb}$ )

Additional file 2: Quantification data details of all the proteins identified in roots of 101.14 and M4 rootstock genotypes. (XLSX $226 \mathrm{~kb}$ )
Additional file 3: Assignment of the functional bin code category of all proteins identified in roots of 101.14 and M4 rootstock genotypes (Table S3A and B) and functional classification of proteins showing significant changes in responses to WS (Table S3C). (XLSX $190 \mathrm{~kb}$ )

Additional file 4: Data details of metabolites identified in roots of 101.14 and M4 rootstock genotypes. (XLSX 19 kb)

\section{Abbreviations}

ABA: Abscisic acid; FA: Formic acid; GABA: $\gamma$-Aminobutyric acid; GMD: Golm Metabolome Database; GST: Glutathione S-transferases; NCBI: National center for biotechnology information; nLC-nESI-MS/MS: Nanoflow liquid chromatography-mass spectrometry; PAGE: PolyAcrylamide Gel Electrophoresis; ROS: Reactive Oxygen Species; SDS: Sodium dodecyl sulfate; SI: Spectrum Intensity; WS: Water stress

\section{Acknowledgements}

The authors thank Živa Ramšak (Department of Biotechnology and Systems Biology, National Institute of Biology, 1000 Ljubljana, Slovenia), member of GoMapMan staff, http://www.gomapman.org/, for providing mapping file of Vitis vinifera. The authors thank Dr. Silvia Morgutti (University of Milan) and Dr. Lesley Currah for polishing the English in the manuscript.

Funding

This work was supported by "AGER- SERRES Project", grant n 2010-2105.

\section{Availability of data and materials}

The data set supporting results from this study can be found within both the article and Additional files 1, 2, 3, and 4 .

\section{Authors' contributions}

$\mathrm{BP}$ contributed to the conception of the study, conceived the experimental design, carried out protein extraction, SDS-PAGE, protein characterization by LC-ESI-MS/MS, analyzed the MS data and participated in writing the manuscript. ASN performed the metabolomic analyses. LE contributed to the conception of study, coordinated the experiments, determined sucrose, wrote and edited the manuscript. OF and AS participated in the manuscript revision. All authors read and approved the final manuscript.

Ethics approval and consent to participate

Not applicable.

\section{Consent for publication}

Not applicable.

\section{Competing interests}

The authors declare that they have no competing interests.

\section{Publisher's Note}

Springer Nature remains neutral with regard to jurisdictional claims in published maps and institutional affiliations.

Received: 4 December 2017 Accepted: 6 June 2018

Published online: 20 June 2018

\section{References}

1. Chaves MM, Santos TP, Souza CR, Ortuño MF, Rodrigues ML, Lopes CM, Maroco JP, Pereira JS. Deficit irrigation in grapevine improves water-use efficiency while controlling vigour and production quality. Ann Appl Biol. 2007;150:237-52. https://doi.org/10.1111/j.1744-7348.2006.00123.x.

2. Flexas JJ, Galmés J, Gallé A, Gulías J, Pou A, Ribas-Carbo M, Tomás M, Medrano H. Improving water use efficiency in grapevines: potential physiological targets for biotechnological improvement. Aust J Grape Wine R. 2010;16:106-21. https://doi.org/10.1111/j.1755-0238.2009.00057.x.

3. Chaves MM, Zarrouk O, Francisco R, Costa JM, Santos T, Regalado AP, Rodrigues ML, Lopes CM. Grapevine under deficit irrigation: hints from physiological and molecular data. Ann Bot. 2010;105:661-76. https://doi.org/ 10.1093/aob/mcq030. 
4. Schultz HR, Stoll M. Some critical issues in environmental physiology of grapevines: future challenges and current limitations. Aust J Grape Wine. 2010;16:4-24. https://doi.org/10.1111/j.1755-0238.2009.00074.x.

5. Castellarin SD, Matthews MA, Di Gaspero G, Gambetta GA. Water deficits accelerate ripening and induce changes in gene expression regulating flavonoid biosynthesis in grape berries. Planta. 2007;227:101-12. https://doi. org/10.1007/s00425-007-0598-8

6. Jones GV, White MA, Cooper OR, Storchmann K. Climate change and global wine quality. Clim Chang. 2005;73:319-43. https://doi.org/10.1007/s10584005-4704-2.

7. Chaves M, Maroco JP, Pereira JS. Understanding plant responses to drought - from genes to the whole plant. Funct Plant Biol. 2003;30: 239-64. https://doi.org/10.1071/FP02076.

8. Cramer GR. Abiotic stress and plant responses from the whole vine to the genes. Aust J Grape Wine R. 2010;16:86-93. https://doi.org/10.1111/j.17550238.2009.00058.x.

9. Lovisolo C, Perrone I, Carra A, Ferrandino A, Flexas J, Medrano H, Schubert A. Drought-induced changes in development and function of grapevine (Vitis spp.) organs and in their hydraulic and non-hydraulic interactions at the whole-plant level: a physiological and molecular update. Funct Plant Biol. 2010;37:98-16. https://doi.org/10.1071/FP09191.

10. Skirycz A, Inzé D. More from less: plant growth under limited water. Curr Opin Biotechnol. 2010;21:197-203. https://doi.org/10.1016/j.copbio.2010.03.002.

11. Munns R. Plant adaptation to salt and water stress: differences and commonalities. Adv Bot Res. 2011;57:1-32. https://doi.org/10.1016/B978-012-387692-8.00001-1.

12. Kantar M, Lucas SJ, Budak H. Drought stress molecular genetics and genomics approaches. Adv Bot Res. 2011;57:445-93. https://doi.org/10.1016/ B978-0-12-387692-8.00013-8.

13. Serra I, Strever A, Myburgh PA, Deloire A. Review: the interaction between rootstocks and cultivars (Vitis vinifera L.) to enhance drought tolerance in grapevine. Aust J Grape Wine R. 2014;20:1-14. https://doi. org/10.1111/ajgw.12054

14. Schachtman DP, Goodger JQD. Chemical root to shoot signalling under drought. Trends Plant Sci. 2008;13:281-7. https://doi.org/10.1016/j.tplants. 2008.04.003.

15. Osakabe Y, Osakabe K, Shinozaki K, Lam-Son PT. Response of plants to water stress. Front Plant Sci. 2014;5:3. https://doi.org/10.3389/fpls.2014.00086.

16. Neumann PM. Recent advances in understanding the regulation of wholeplant growth inhibition by salinity, drought and colloid stress. Adv Bot Res 2011;57:33-48. https://doi.org/10.1016/B978-0-12-387692-8.00002-3.

17. Miller G, Suzuki N, Ciftci_Yilmaz S, Mittler R. Reactive oxygen species homeostasis and signalling during drought and salinity. Plant Cell Environ. 2010;33:453-67. https://doi.org/10.1111/j.1365-3040.2009.02041.x.

18. Cramer GR, Van Sluyter SC, Hopper DW, Pascovici D, Keighley T, Haynes PA. Proteomic analysis indicates massive changes in metabolism prior to the inhibition of growth and photosynthesis of grapevine (Vitis vinifera L.) in response to water deficit. BMC Plant Biol. 2013;13:49. https://doi.org/10. 1186/1471-2229-13-49.

19. Gambetta GA, Manuck CM, Drucker ST, Shaghasi T, Fort K, Matthews MA, Walker MA, McElron AJ. The relationship between root hydraulics and scion vigour across Vitis rootstocks: what role do root aquaporins play? J Exp Bot. 2012;63:6445-55. https://doi.org/10.1093/jxb/ers312.

20. Aroca R, Porcel R, Ruiz-Lozano JM. Regulation of root water uptake under abiotic stress conditions. J Exp Bot. 2011;66:5739-52. https://doi.org/10. 1093/jxb/err266

21. Alasina MM, Smart DR, Bauerle T, de Herralde F, Biel C, Stockert C, Negron C, Save R. Seasonal changes of whole root system conductance by a droughttolerant grape root system. J Exp Bot. 2011;62:99-109. https://doi.org/10. 1093/jxb/erq247.

22. Comas LH, Baurle TL, Eissenstat DM. Biological and environmental factors controlling root dynamics and function: effects of root ageing and soil moisture. Aust J Grape Wine R. 2010;16:131-17. https://doi.org/10.1111/j. 1755-0238.2009.00078.x.

23. Vadez V. Root hydraulics: the forgotten side of roots in drought adaptation. Field Crop Res. 2014;165:15-24. https://doi.org/10.1016/j.fcr.2014.03.017.

24. Gambetta GA, Fei J, Rost TL, Knipfer T, Matthews MA, Shackel KA, Walker MA, McElrone AJ. Water uptake along the length of grapevine fine roots: developmental anatomy, tissue specific aquaporin expression, and pathways of water transport. Plant Physiol. 2013;163:1254-65. https://doi.org/10.1104/pp.113.221283
25. Wu Y, Cosgrove DJ. Adaptation of roots to low water potentials by changes in cell wall extensibility and cell wall proteins. J Exp Bot. 2000;51:1543-53. https://doi.org/10.1093/jexbot/51.350.1543.

26. Ober ES, Sharp RE. Regulation of root growth responses to water deficit. In: Jenks MA, Hasegawa PM, Jain SM, editors. Advances in molecular breeding toward drought and salt tolerant crops; 2007. p. 33-53. ISBN: 978-1-4020-5578-2

27. Regier N, Streb S, Cocozza C, Schaub M, Cherubini P, Zeeman SC, Frey B. Drought tolerance of two black poplar (Populus nigra L.) clones: contribution of carbohydrates and oxidative stress defence. Plant Cell Environ. 2009;32:1724-36. https://doi.org/10.1111/j.1365-3040.2009.02030.x.

28. Yamaguchi M, Sharp RE. Complexity and coordination of root growth at low water potentials: recent advances from transcriptomic and proteomic analyses. Plant Cell Environ. 2010;33:590-603. https://doi.org/10.1111/j.1365-3040.2009. 02064.x.

29. Meggio F, Prinsi B, Negri AS, Simone Di Lorenzo G, Lucchini G, Pitacco A, Failla O, Scienza A, Cocucci M, Espen L. Different biochemical and physiological responses of two grapevine rootstock genotypes to drought and salt treatments. Aust J Grape Wine R. 2014;20:310-23. https://doi.org/10. 1111/ajgw.12071.

30. Corso M, Vannozzi A, Maza E, Vitulo N, Meggio F, Pitacco A, Telatin A, D’Angelo M, Feltrin E, Negri AS, Prinsi B, Valle G, Ramina A, Bouzayen M, Bonghi C, Lucchin M. Comprehensive transcript profiling of two grapevine rootstock genotypes contrasting in drought susceptibility links the phenylpropanoid pathway to enhanced tolerance. J Exp Bot. 2015;66:43-57. https://doi.org/10.1093/jxb/erv274.

31. Ghosh D, Xu J. Abiotic stress responses in plant roots: a proteomics perspective. Front Plant Sci. 2014;5:6. https://doi.org/10.3389/fpls.2014.00006.

32. Vincent $D$, Ergül A, Bohlman MC, Tattersall EAR, Tillett RL, Wheatley MT, Woolsey R, Quilici DR, Joets J, Schlauch K, Schooley DA, Cushman JC, Cramer GR. Proteomic analysis reveals differences between Vitis vinifera L. CV. Chardonnay and cv. Cabernet Sauvignon and their responses to water deficit and salinity. J Exp Bot. 2007;58:1873-92. https://doi.org/10.1093/jxb/erm012.

33. Grimplet J, Wheatley MD, Jouira HB, Deluc LG, Cramer GR, Cushman JC. Proteomic and selected metabolite analysis of grape berry tissues under well-watered and water-deficit stress conditions. Proteomics. 2009;9:2503-28. https://doi.org/10.1002/pmic.200800158.

34. Thimm O, Bläsing $O$, Gibon A, Nagel A, Meyer S, Krüger P, Selbing J, Müller LA, Rhee SEY, Stitt M. MAPMAN: a user-driven tool to display genomics data sets onto diagrams of metabolic pathways and other biological processes. Plant J. 2004;37:914-39. https://doi.org/10.1111/j.1365-313X.2004.02016.x.

35. Rösti J, Barton CJ, Albrecht S, Dupree P, Pauly M, Findlay K, Roberts K, Seifert GJ. UDP-glucose 4-epimerase isoforms UGE2 and UGE4 cooperate in providing UDP-galactose for cell wall biosynthesis and growth of Arabidopsis thaliana. Plant Cell. 2007;19:1565-79. https://doi.org/10.1105/tpc.106.049619.

36. Plaxton WC. The organization and regulation of plant glycolisis. Annu Rev Plant Physiol Plant Mol Biol. 1996;47:185-214. https://doi.org/10.1146/ annurev.arplant.47.1.185.

37. Kirch HH, Bartels D, Wei J, Schnable PS, Wood AJ. The ALDH gene superfamily of Arabidopsis. Trends Plant Sci. 2004;9:371-7. https://doi.org/10. 1016/j.tplants.2004.06.004.

38. Kavar T, Maras M, Kidrič M, Šuštar-Vozlič J, Meglic V. Identification of genes involved in the response of leaves of Phaseolus vulgaris to drought stress. Mol Breed. 2008;21:159-72. https://doi.org/10.1007/s11032-007-9116-8.

39. McDonald AE, Vanlerberghe GC. The organization and control of plant mitochondrial metabolism. In: Planxoton WC, McManus MT, editors. Control of primary metabolism in plants. Annual plant reviews; 2006. p. 290-324. ISBN: 978-1-405e1-3096-7.

40. Zhang W, Qin C, Zhao J, Wang X. Phospholipase Da1-derived phosphatidic acid interacts with $\mathrm{ABI1}$ phosphatase $2 \mathrm{C}$ and regulates abscisic acid signalling. PNAS. 2004;101:9508-13. https://doi.org/10.1073/pnas.0402112101.

41. Winter G, Todd CD, Trovato M, Forlani G, Funck D. Physiological implications of arginine metabolism in plants. Front Plant Sci. 2015;6:534. https://doi.org/ 10.3389/fpls.2015.00534

42. González-Cabanelas D, Wright LP, Paetz C, Onkokesung N, Gershenzon J, Rodríguez-Concepción M, Phillips MA. The diversion of 2-C-methyl-D-erythritol2,4-cyclodiphosphate from the 2-C methyl-D-erythritol 4-phosphate pathway to hemiterpene glycosides mediates stress responses in Arabidopsis thaliana. Plant J. 2015;82:122-37. https://doi.org/10.1111/tpj.12798.

43. Mano J, Belles-Boix E, Babiychuk E, Inzé D, Torii Y, Hiraoka E, Takimoto K, Slooten L, Asada K, Kushnir S. Protection against fhotooxidative injury of tobacco leaves by 2-alkenal reductase. Detoxication of lipid peroxide- 
derived reactive carbonyls. Plant Physiol. 2005;139:1773-83. https://doi.org/ 10.1104/pp.105.070391.

44. Turner JG, Ellis C, Devoto A. The Jasmonate signal pathway. Plant Cell. 2002; 14:S153-64. https://doi.org/10.1105/tpc.000679.

45. Hedden P, Thomas G. Gibberellin biosynthesis and its regulation. Biochem J. 2012;444:11-25. https://doi.org/10.1042/BJ20120245.

46. Chen C-N, Chu C-C, Zentella R, Pan S-M, Ho DT-H. AtHVA22 gene family in Arabidopsis: phylogenetic relationship, ABA and stress regulation, and tissuespecific expression. Plant Mol Biol. 2002;49:633-44. https://doi.org/10.1023/A: 1015593715144.

47. Dixon DP, Davis BG, Edwards R. Functional divergence in the glutathione transferase superfamily in plants. J Biol Chem. 2002;277:30859-69. https:// doi.org/10.1074/jbc.M202919200.

48. Miller EA, Beilharz TH, Malkus PN, Lee MCS, Hamamoto S, Orci SR. Multiple cargo binding sites on the COPII subunit Sec24p ensure capture of diverse membrane proteins into transport vesicles. Cell. 2003;1 14:497-509. https:// doi.org/10.1016/S0092-8674(03)00609-3.

49. Schaller A. A cut above the rest: the regulatory function of plant proteases. Planta. 2004;220:183-97. https://doi.org/10.1007/s00425-004-1407-2.

50. Dwivedi RS, Breiman A, Herman EM. Differential distribution of the cognate and heat stress induced isoforms of high Mr cis-trans prolyl peptidyl isomerase (FKBP) in the cytoplasm and nucleoplasm. J Exp Bot. 2003;54: 2679-89. https://doi.org/10.1093/jxb/erg307.

51. Kamei CLA, Boruc J, Vandepoele K, Van den Daele H, Maes S, Russinova E, Inzé D, De Veylder L. The PRA1 gene family in Arabidopsis. Plant Physiol. 2008;147:1735-49. https://doi.org/10.1104/pp.108.122226.

52. Marti L, Fornaciari S, Renna L, Stefano G, Brandizzi F. COPII-mediated traffic in plants. Trends Plant Sci. 2010;15:522-8. https://doi.org/10.1016/j.tplants. 2010.05.010

53. Dunwell JM, Gibbings JG, Mahmood T, Naqvi SMS. Germin and germin-like proteins: evolution, structure, and function. Crit Rev Plant Sci. 2008;27:342-75. https://doi.org/10.1080/07352680802333938.

54. Kim HS, Yu Y, Snesrud EC, Moy LP, Linfor LD, Haas BJ, Nierman WC, Quackenbus J. Transcriptional divergence of the duplicated oxidative stressresponsive genes in the Arabidopsis genome. Plant J. 2005;41:212-20. https://doi.org/10.1111/j.1365-313X.2004.02295.X.

55. Chen JY, Dai XF. Cloning and characterization of the Gossypium hirsutum major latex protein gene and functional analysis in Arabidopsis thaliana. Planta. 2010;231:861-73. https://doi.org/10.1007/s00425-009-1092-2.

56. Wang Y, Li Y, Chen X, Ye T, Zhong B, Liu R, Wu Y, Chan Z. Major latex protein-like protein 43 (MLP43) functions as a positive regulator during abscisic acid responses and confers drought tolerance in Arabidopsis thaliana. J Exp Bot. 2016;67:421-34. https://doi.org/10.1093/jxb/erv477.

57. Barthakur S, Babu V, Bansal KC. Over-expression of osmotin induces proline accumulation and confers tolerance to osmotic stress in transgenic tobacco. J Plant Biochem Biotechnol. 2001;10:31-7. https://doi.org/10.1007/BF03263103.

58. Kumar SA, Kumari PH, Kumar GS, Mohanalatha C, KaviKishor PB. Osmotin: a plant sentinel and a possible agonist of mammalian adiponectin. Front Plant Sci. 2015;6:163. https://doi.org/10.3389/fpls.2015.00163.

59. Bartels D, Sunkar R. Drought and salt tolerance in plants. Crit Rev Plant Sci. 2005;24:23-58. https://doi.org/10.1080/07352680590910410.

60. Conde A, Regalado A, Rodrigues D, Costa JM, Blumwald E, Chaves MM, Gerós H. Polyols in grape berry: transport and metabolic adjustments as a physiological strategy for water-deficit stress tolerance in grapevine. J Exp Bot. 2015;66:889-906. https://doi.org/10.1093/jxb/eru446.

61. Wang W, Vinocur B, Altman A. Plant responses to drought, salinity and extreme temperatures: towards genetic engineering for stress tolerance. Planta. 2003;218:1-14. https://doi.org/10.1007/s00425-003-1105-5.

62. Vandeleur RK, Mayo G, Shelden MC, Gilliham M, Kaiser BN, Tyerman SD. The role of plasma membrane intrinsic protein aquaporins in water transport through roots: diurnal and drought stress responses reveal different strategies between isohydric and anisohydric cultivars of grapevine. Plant Physiol. 2009;149:445-60. https://doi.org/10.1104/pp.108.128645.

63. Vishwanath SJ, Delude C, Domergue F, Rowland O. Suberin: biosynthesis, regulation, and polymer assembly of a protective extracellular barrier. Plant Cell Rep. 2015;34:573-86. https://doi.org/10.1007/s00299-014-1727-z.

64. Peleg Z, Blumwald E. Hormone balance and abiotic stress tolerance in crop plants. Curr Opin Plant Biol. 2011;14:290-5. https://doi.org/10.1016/.jpbi.2011.02.001.

65. Tanimoto E. Regulation of root growth by plant hormones-roles for auxin and gibberellin. Crit Rev Plant Sci. 2013;24:249-65. https://doi.org/10.1080/ 07352680500196108
66. Wasternack C. Jasmonates: an update on biosynthesis, signal transduction and action in plant stress response, growth and development. Ann Bot. 2007;100:681-97. https://doi.org/10.1093/aob/mcm079.

67. Liu R, Chen S, Jiang J, Zhu L, Zheng C, Han S, Gu J, Sun J, Li H, Wang H, Song A, Chen F. Proteomic changes in the base of chrysanthemum cuttings during adventitious root formation. BMC Genomics. 2013;14:919. https://doi.org/10. 1186/1471-2164-14-919.

68. Neuhaus HE, Emes MJ. Nonphotosynthetic metabolism in plastids. Annu Rev Plant Physiol Plant Mol Biol. 2000;51:111-40. https://doi.org/10.1146/ annurev.arplant.51.1.111.

69. Millar AH, Siedow JN, Day D. Respiration and photorespiration. In: Buchanan BB, Gruissem W, Jones RL, editors. Biochemistry \& molecular biology of plants; 2015. p. 610-55. ISBN: 9780470714218.

70. Araújo WL, Tohge T, Ishizaki K, Leaver CJ, Fernie AR. Protein degradation - an alternative respiratory substrate for stressed plants. Trends Plant Sci. 2011;16: 489-98. https://doi.org/10.1016/j.tplants.2011.05.008.

71. Brunner I, Herzog C, Dawes MA, Arend M, Sperisen C. How tree roots respond to drought. Front Plant Sci. 2015;6:547. https://doi.org/10.3389/fpls. 2015.00547.

72. Atkin OK, Macherel $\mathrm{D}$. The crucial role of plant mitochondria in orchestrating drought tolerance. Ann Bot. 2009;103:581-97. https://doi.org/ 10.1093/aob/mcn094.

73. Wang Y, Zhang $X$, Lu S, Wang M, Wang L, Wang W, Cao F, Chen H, Wang J, Zhang J, Tu J. Inhibition of a basal transcription factor 3-like gene Osj10gBTF3 in rice results in significant plant miniaturization and typical pollen abortion. Plant Cell Physiol. 2012;53:2073-89. https://doi. org/10.1093/pcp/pcs 146 .

74. Carrol AJ. The Arabidopsis cytosolic ribosomal proteome: from form to function. Front Plant Sci. 2013;4:32. https://doi.org/10.3389/fpls.2013.00032.

75. Kaushik D, Aryadeep R. Reactive oxygen species (ROS) and response of antioxidants as ROS-scavengers during environmental stress in plants. Front Plant Sci. 2014;2:53. https://doi.org/10.3389/fenvs.2014.00053.

76. Liu JJ, Ekramoddoullah AKM. The family 10 of plant pathogenesis-related proteins: their structure, regulation, and function in response to biotic and abiotic stresses. Physiol Mol Plant Pathol. 2006;68:3-13. https://doi.org/10. 1016/j.pmpp.2006.06.004.

77. Radauer $\mathrm{C}$, Lackner $\mathrm{P}$, Breiteneder $\mathrm{H}$. The Bet $\vee 1$ fold: an ancient, versatile scaffold for binding of large, hydrophobic ligands. BMC Evol Biol. 2008;8: 286. https://doi.org/10.1186/1471-2148-8-286.

78. Inui H, Sawada M, Goto J, Yamazaki K, Kodama N, Tsuruta H, Eun H. A major latex-like protein is a key factor in crop contamination by persistent organic pollutants. Plant Physiol. 2013;161:2128-35. https://doi.org/10.1104/pp.112.213645.

79. Lorenz WW, Sun F, Liang C, Kolychev D, Wang H, Zhao X, Cordonnier-Pratt MM, Pratt LH, Dean GFD. Water stress-responsive genes in loblolly pine (Pinus taeda) roots identified by analyses of expressed sequence tag libraries. Tree Physiol. 2006;26:1-16. https://doi.org/10.1093/treephys/26.1.1.

80. Gregorová Z, Kováčik J, Klejdus B, Maglovski M, Kuna R, Hauptvogel P, Matušíková I. Drought-induced responses of physiology, metabolites, and PR proteins in Triticum aestivum. J Agric Food Chem. 2015;63:8125-33. https://doi.org/10.1021/acs.jafc.5b02951.

81. Davidson RM, Reeves PA, Manosalva PM, Leach JN. Germins: a diverse protein family important for crop improvement. Plant Sci. 2009;177:499-510. https://doi.org/10.1016/j.plantsci.2009.08.012.

82. Lu M, Han YP, Gao JG, Wang XJ, Li WB. Identification and analysis of the germin-like gene family in soybean. BMC Genomics. 2010;11:620. https://doi. org/10.1186/1471-2164-11-620.

83. Timperio AM, Egidi MG, Zolla L. Proteomics applied on plant abiotic stresses: role of heat shock proteins (HSP). J Proteome. 2008;71:391-411. https://doi.org/10.1016/j.jprot.2008.07.005.

84. Ma C, Haslbeck M, Babujee L, Jahn O, Reumann S. Identification and characterization of a stress-inducible and constitutive small heat-shock protein targeted to the matrix of plant peroxisomes. Plant Physiol. 2006;141: 47-60. https://doi.org/10.1104/pp.105.073841.

85. Prinsi B, Negri AS, Quattrocchio FM, Koes RE, Espen L. Proteomics of red and white corolla limbs in petunia reveals a novel function of the anthocyanin regulator ANTHOCYANIN1 in determining flower longevity. J Proteome. 2016;131:38-47. https://doi.org/10.1016/j.jprot.2015.10.008.

86. Laemmli UK. Cleavage of structural proteins during the assembly of the head of bacteriophage. T4. Nature. 1970;227:680-5. https://doi.org/10.1038/227680a0.

87. Neuhoff $V$, Arold N, Taube D, Ehrhardt W. Improved staining of proteins in polyacrylamide gels including isoelectric focusing gels with clear 
background at nanogram sensitivity using Coomassie Brilliant Blue G-250 and R-250. Electrophoresis. 1988;9:255-62. https://doi.org/10.1002/elps. 1150090603

88. Prinsi B, Negri AS, Pesaresi P, Cocucci M, Espen L. Evaluation of protein pattern changes in roots and leaves of Zea mays plants in response to nitrate availability by two-dimensional gel electrophoresis analysis. BMC Plant Biol. 2009;9:113. https://doi.org/10.1186/1471-2229-9-113.

89. Lisec J, Schauer N, Kopka J, Willmitzer L, Fernie AR. Gas chromatography mass spectrometry-based metabolite profiling in plants. Nat Protoc. 2006;1 387-96. https://doi.org/10.1038/nprot.2006.59.

90. Negri AS, Prinsi B, Failla O, Scienza A, Espen L. Proteomic and metabolic traits of grape exocarp to explain different anthocyanin concentrations of the cultivars. Front Plant Sci. 2015;6:603. https://doi.org/10.3389/fpls.2015.00603.

91. Hiller K, Hangebrauk J, Jäger C, Spura J, Schreiber K, Schomburg D. MetaboliteDetector: comprehensive analysis tool for targeted and nontargeted gc/ms based metabolome analysis. Anal Chem. 2009;81:3429-39. https://doi.org/10.1021/ac802689c.

92. Hummel J, Selbig J, Walther D, Kopka J. The Golm metabolome database: a database for GC-MS based metabolite profiling. In: Nielsen J, Jewett MC, editors. Topics in current genetics, Vol. 18: metabolomics; 2009. p. 75-95. https://doi.org/10.1007/4735_2007_0229.

93. Nelson NA. A photometric adaptation of the Somogy method for the determination of glucose. JBC. 1944;153:375-84. http://www.jbc.org/ content/153/2/375.short\#ref-list-1

94. Caraux G, Pinloche S. PermutMatrix: a graphical environment to arrange gene expression profiles in optimal linear order. Bioinformatics. 2005;21: 1280-1. https://doi.org/10.1093/bioinformatics/bti141.

95. Meunier B, Dumas E, Piec I, Béchet D, Hébraud M, Hocquette JF. Assessment of hierarchical clustering methodologies for proteomic data mining. J Proteome Res. 2007;6:358-66. https://doi.org/10.1021/pr060343h.

\section{Ready to submit your research? Choose BMC and benefit from:}

- fast, convenient online submission

- thorough peer review by experienced researchers in your field

- rapid publication on acceptance

- support for research data, including large and complex data types

- gold Open Access which fosters wider collaboration and increased citations

- maximum visibility for your research: over $100 \mathrm{M}$ website views per year 